\title{
Processing Across the Language Boundary: A Cross-Modal Priming Study of Spanish-English Bilinguals
}

\author{
Arturo E. Hernandez, Elizabeth A. Bates, and Luis X. Avila \\ University of California, San Diego
}

\begin{abstract}
A cross-modal naming paradigm was used to assess within- and between-language sentential priming in Spanish-English bilinguals. The paradigm used single-language auditory texts with visual target words under normal, visually degraded, speeded, and delayed naming conditions. Cross-language priming was always observed when the target language was predictable (in the blocked condition), even under speeded conditions. When the target language was unpredictable (in the mixed condition), cross-language priming was observed only when response was delayed (delayed naming) and under a subset of conditions when word recognition was delayed (visual degradation). Results are compatible with the idea that cross-language priming in a sentence context is more likely to involve the use of expectations, strategic processes, or both that allow bilinguals to tune themselves to external conditions. There are enough exceptions to the general rule, however, to warrant a reconsideration of the lexical-postlexical dichotomy. Implications for modular versus interactive models of lexical access are discussed.
\end{abstract}

This article desribes a series of experiments exploring the conditions under which priming occurs in bilingual individuals. The inquiry requires consideration of issues in lexical access for both monolingual and bilingual speakers. We begin with a review of current issues in lexical access in general before proceeding to issues that directly apply to priming in bilingual populations.

\section{Lexical Access in Monolingual Speakers}

A common paradigm for the investigation of on-line language processing is the semantic-priming task. In this task, participants are shown a word pair that is either related (cat-dog) or unrelated (bulb-dog). Numerous studies have found that college-aged adults are faster to pronounce or make a lexical decision about the second word in a related word pair than they are for the second word of an unrelated word pair (see Neely, 1991, for a review). These studies have yielded information about the word-recognition process and about basic cognitive mechanisms that accompany word recognition (e.g., spreading activation). Despite the robustness of the semantic-priming effect, a number of controversial issues have arisen in the word-recognition literature. These issues include

Arturo E. Hernandez, Elizabeth A. Bates, and Luis X. Avila, Center for Research in Language, University of California, San Diego.

Support for this research was provided by National Institutes of Health/National Institute on Deafness and Other Communication Disorders Grant 2-RO1-DC00216-10 and by a minority supplement in association with that grant. We would like to thank Nydia Contreras, Iliana Reyes, and Care Udell for their assistance in data collection and Larry Juarez and Robert Buffington for technical support. Finally, we would like to thank Javier Movellan for helpful comments on earlier versions of this article.

Correspondence concerning this article should be addressed to Arturo E. Hernandez, Center for Research in Language 0526, University of California, San Diego, La Jolla, California 92093-0526. Electronic mail may be sent via Internet to arturo@crl.ucsd.edu. the modularity (or nonmodularity) of lexical access, the influence of strategic factors on semantic priming, and the locus of lexical- and sentence-level priming effects. All of these issues have a profound impact on the investigation of bilingual language processing. Yet, only a few have been addressed with bilingual speakers.

Some researchers have suggested that comprehension in language processing takes place in two nonoverlapping stages, one lexical and the other postlexical. Within this framework, lexical access is highly modular (i.e., an automatic, bottom-up, fast perceptual process by which the lexical forms themselves are identified). The factors contributing to automatic lexical access are believed to include spreading semantic activation within the lexicon (i.e., from the prime to the target), together with the buildup of information about the physical form of the word (orthographic, phonological, or both). Lexical effects are followed by a process of integration, which includes the insertion of a word into a larger semantic context (i.e., a sentential- or discourse-level context) and modifications of the listener's current understanding and beliefs to accommodate the newly added information. The term postlexical indicates the open-ended nature of this integration process, which is believed to be controlled, top-down, conscious, and highly penetrable by a general message processor. Within this twostage framework, there is a "magic moment" (see Balota, 1989, for a review) at which the lexical form has been accessed before further semantic processing occurs.

A number of empirical tests have been used to differentiate between lexical priming and postlexical effects relevant to the present investigation of within- and between-language priming in bilinguals (see Table 1 for a summary).

First, it follows from the terms lexical and postlexical that there should be some temporal disparity between these two stages with faster and earlier reaction times for automatic lexical effects and slower reaction times for postlexical effects. However, one cannot simply conclude that an effect is automatic because of its absolute speed (i.e., because it is very fast). 
Table 1

Empirical Tests of the Distinction Between Lexical and Postlexical Priming Effects and Predictions for Within-Versus Between-Language Priming

\begin{tabular}{|c|c|c|}
\hline Variable & Assumption & Prediction \\
\hline Reaction time (RT) & $\begin{array}{l}\text { Lexical = fast } \\
\text { Postlexical = slow }\end{array}$ & Within RT $<$ between RT \\
\hline Expectations & $\begin{array}{l}\text { Low expectations }=\text { lexical only } \\
\text { High expectations }=\text { lexical and } \\
\text { postlexical }\end{array}$ & $\begin{array}{l}\text { Priming within but not between } \\
\text { Priming within and between } \\
\text { Within }>\text { between (additivity) }\end{array}$ \\
\hline Visual degradation & $\begin{array}{l}\text { Allows spreading activation to build, } \\
\text { affects lexical but not postlexical }\end{array}$ & Increased priming for within only \\
\hline Delayed naming & $\begin{array}{c}\text { Allows strategies to apply, affects } \\
\text { postlexical but not lexical }\end{array}$ & Increased priming for between and within \\
\hline Speeded naming & Insufficient time for strategies to apply & $\begin{array}{l}\text { No effect on within } \\
\text { Decreased priming or no priming for } \\
\text { between only }\end{array}$ \\
\hline Direction of priming & $\begin{array}{l}\text { Facilitation = lexical and postlexical } \\
\text { Inhibition = postlexical only }\end{array}$ & $\begin{array}{l}\text { Within > between (additivity) } \\
\text { Between only }\end{array}$ \\
\hline
\end{tabular}

The key insight here is that lexical effects should be faster than postlexical effects within the confines of a given experiment (i.e., a relative difference in speed).

Second, automatic lexical processes should not be affected by expectations, whereas postlexical processes should be amenable to strategic effects. In a number of studies, expectations have been induced by manipulating the proportion of semantically related trials, the number of nonword trials in a given experiment, or both (Neely, Keefe, \& Ross, 1989; Seidenberg, Waters, Sanders, \& Langer, 1984). When the number of related trials is relatively low, priming is assumed to reflect an automatic and unconscious process (e.g., the spread of semantic activation within a lexical network). When the number of related trials is high, priming may be contaminated by conscious, strategic effects (i.e., participants expect the prime and target to be related). Semantic priming has been observed under both high- and low-relatedness conditions, but effects are typically smaller when related pairs are relatively rare (so rare that individuals may not be aware of them at all). This result follows from assumptions about additivity that are often left unstated in studies of this kind. By definition, the automatic component of semantic priming cannot be enhanced or suppressed through expectations. Hence, strategic factors can only add to the automatic priming component; they cannot replace nor inhibit automatic priming. We return to this point later in our comparison of within- and between-language priming in bilinguals.

Third, researchers have found that slowing of the wordrecognition process through visual degradation increases the size of semantic priming (Becker \& Killion, 1977; Meyer, Schvaneveldt, \& Ruddy, 1975; Stanovich \& West, 1983). It is generally argued that this increase in priming is a true lexical effect reflecting a "horse race" between two kinds of automatic activation: spreading semantic activation at the lexical level and bottom-up activation from orthography to lexical form. When orthographic decoding is artificially slowed by visual degradation (e.g., placing asterisks between the letters in a word), then semantic activation has more time to spread from the prime to related words in the lexicon (including the emerging word target). Within this framework, degradation should increase lexical effects but should have no measurable effect on postlexical processing.

Fourth, manipulations of stimulus and response timing have played an important role in distinguishing between lexical and postlexical effects. If true lexical priming is early and automatic, then we should expect it to occur only within an early and relatively limited time window. Hence, automatic effects are more likely to emerge with a short stimulus onset asychrony (SOA, referring to the time between onset of the prime and onset of the target), and these effects are more likely when participants are forced to respond very quickly. Postlexical effects are more likely to emerge at longer SOAs, following a response delay, or both. This is true because postlexical processes are (by definition) relatively late and because they can be maintained indefinitely through strategic enhancement. Hence, large increases in the SOA or an artificial delay in response should increase the magnitude of controlled, postlexical priming. Conversely, when individuals are given very short SOAs, when they have very little time to respond, or both, automatic effects should still be evident, whereas controlled effects should decrease or disappear altogether.

Finally, differences in direction of priming have also been used to distinguish between lexical and postlexical effects. Specifically, short SOAs tend to elicit facilitation without inhibition (relative to some baseline), which is a signature pattern for automatic lexical effects according to Posner and Snyder (1975). With longer SOAs, facilitation and inhibition are both observed, suggesting that reaction times are affected by a combination of automatic and strategic processes (Favreau \& Segalowitz, 1983; Smith, Theodor, \& Franklin, 1983). Unfortunately, these predictions rest on some equivocal assumptions: (a) that it is possible to find a true neutral baseline from which facilitation and inhibition can be measured, (b) that rapid inhibitory effects do not exist, and (c) that lexical priming is truly an automatic process. The first point has been widely discussed in the priming literature, but there is still little consensus regarding the right baseline to use. This problem is bad enough at the single-word level (see Neely, 1991, for a discussion), but it is magnified many times over when priming is assessed in a larger sentence or discourse context (see 
below). What, after all, is a neutral paragraph? The second point has received less attention, but it is equally problematic. Contrary to the assumption that all inhibition emanates from slow processes, rapid inhibitory effects have now been demonstrated in several domains, including nonlinguistic tests of color priming (Marangolo, Di Pace, \& Pizzamiglio, 1993) and picture-word Stroop tasks with a very short SOA (Glaser, 1992). Third, in recent years the automaticity of lexical priming has been called into question. For example, Smith, Besner, and Miyoshi (1994) have found that automatic priming is affected by changes in the proportion of short and long SOA trials in a given block. Furthermore, it has been shown that cognitive overload from a secondary task can affect semantic priming (Henik, Tzelgov, Friedrich, \& Levi-Manor, 1994). For these reasons, we are convinced that tests of the two-stage model must rest on variations of timing, expectations, and stimulus quality. In addition, it is not clear that lexical priming should be called an automatic process and that postlexical priming should be called a controlled process.

As we have described it so far, the lexical-postlexical dichotomy applies to studies that have investigated priming between related words. Another source of controversy surrounds the locus of sentence-level and discourse-level context effects. For example, Swinney and his colleagues have argued that sentential effects apply only after all the meanings of an ambiguous word have been exhaustively accessed, which is in line with the two-stage model (Swinney, 1979; Seidenberg, Tanenhaus, Leiman, \& Bienkowski, 1982). However, a number of studies suggest that larger sentential contexts do have an influence on lexical access, producing a rapid, "facilitationonly" pattern of priming with effects of degradation, variations in timing, or both that are very similar to those found in the lexical-priming literature (Duffy, Henderson, \& Morris, 1989; Morris, 1994; Stanovich \& West, 1983). Results like these have led some investigators to suggest that lexical priming and sentential priming may not be the product of separable psychological processes (Hernandez \& Bates, 1994; MarslenWilson \& Tyler, 1987; O'Seaghdha, 1989; Van Petten \& Kutas, 1987). ${ }^{1}$ These competing frameworks are relevant to the present experiments where bilingual priming is assessed in a sentence context under many of the conditions summarized in Table 1.

\section{On Priming in Bilinguals}

A long-standing debate in the psycholinguistic literature on bilingualism revolves around the independence or interdependence of the bilingual's two lexicons. Are there direct links between lexical nodes for words in different languages, or are these words mediated by higher level conceptual processes? Traditionally, this has led to an increased effort to understand whether cross-language priming (gato-dog) is lexical (typically regarded as automatic) or postlexical (typically regarded as controlled). Within this framework, an interdependent bilingual lexicon would allow for activation to spread from Language $\mathrm{A}$ to Language $\mathrm{B}$. In an independent bilingual lexicon, however, all cross-language priming would necessarily be strategic because it would involve activity outside of the lexical module. Investigating whether cross-language priming is strate- gic (i.e., controlled) can be one way to understand the structure of the bilingual lexicon.

Grainger and Beauvillain (1988) were the first to suggest that the difference between cross-language and withinlanguage priming might fit within an automatic-controlled framework. The authors tested bilinguals at different SOAs with a lexical-decision task and found that cross-language priming appeared only at the longer SOA (700 ms), whereas within-language priming appeared at both long and short SOAs. They concluded that within-language processing is automatic, whereas cross-language priming is controlled. A more recent study conducted by Keatley and de Gelder (1992) found that cross-language priming disappears under speededresponse conditions. Both sets of authors have used this as evidence that cross-language priming is a postlexical effect. Within-language priming, on the other hand, is a lexical effect. These findings are compatible with the view that the bilingual lexicon is modular.

Other studies, however, have found evidence of crosslanguage priming early in processing and have concluded that the bilingual lexicon is highly interconnected. Altarriba (1991, 1992) used a short SOA ( $200 \mathrm{~ms})$, a low number of related and unrelated trials, and a low number of words to eliminate the use of strategic processes. Individuals showed conceptual (fruit-manzana), translation (manzana-apple), and semantic priming (manzana-orange) for cross-language conditions. In addition, Tzelgov and Eben-Ezra (1992) have shown that cross-language priming can occur early in processing regardless of a person's conscious expectations. Thus, some studies seem to confirm that cross-language priming is still present early in processing even though it may not be as robust as within-language priming.

The studies described above show that cross-language priming is a variable effect. This could be true for a number of methodological reasons. For example, Grainger and Beauvillain (1988) tested native English speakers who had been speaking French for at least 10 years and had lived in France for at least 2 years. It is not clear, however, how often these individuals used both languages in their daily lives. Altarriba (1992), on the other hand, tested participants who were residents of Miami. These individuals were Spanish dominant but regularly used both languages in everyday life. Thus, although the time that had been spent speaking both languages was equivalent across studies, there may have been clear differences in the regular use of both languages. Second, there may have been differences in task parameters across studies. Grainger and Beauvillain used a delay between prime and target, whereas Altarriba used no delay between prime and target. These small differences in timing could have had an effect on the magnitude of cross-language priming. Despite these differences across studies, it is clear that cross-language priming is less robust than within-language priming.

\footnotetext{
${ }^{1}$ Forster (1990) has argued that all semantic-priming effects are postlexical and involve a decision component. This has been supported by studies that have found that semantic priming is eliminated when participants have to indicate whether a word has an asterisk in front of it (Smith et al., 1983) or whether a prime contained a particular letter (Henik, Friedrich, \& Kellog, 1983).
} 
Given this state of affairs, one might conclude that crosslanguage priming may be too variable to draw any conclusions. That is, it might not offer any insight into the structure of the bilingual lexicon. These problems mirror those in the monolingual literature. That is, it is not clear that within-language priming is a completely automatic process (even for monolinguals) and that cross-language priming is controlled (purely strategic). Yet, there are clear differences in processing withinlanguage words and cross-language words. Furthermore, bilingual language processing necessarily involves a complex set of processing trade-offs that extend beyond the structure of the lexicon itself. Thus, the variability in findings may be part of the variability of processing that is specific to the bilingual condition. Thus, it seems fruitful to investigate the conditions under which cross-language priming appears or does not appear. This is one of the goals of the present experiments.

The present experiments investigate the effect of mixedlanguage (unpredictable) versus blocked-language (highly predictable) conditions on cross-language priming assessed within a discourse-level naming task (i.e., word pronunciation). In this task, participants are asked to listen to a series of texts. During the presentation of any particular text, target words are omitted from the auditory text, and a word that is either congruent or incongruent with the target (semantically, linguistically, or both) appears visually on the screen. This yields four conditions: $+S /+L$ (i.e., the correct word in the text language), $+\mathrm{S} /-\mathrm{L}$ (a translation of the correct word in the other language), $-\mathrm{S} /+\mathrm{L}$ (a semantically anomalous word in the text language), and $-\mathrm{S} /-\mathrm{L}$ (a semantically anomalous word in the other language). In addition to the full $2 \times 2$ design $(+/-S$ vs. $+/-L)$, priming scores can be computed by subtracting reaction times for the semantically appropriate words from reaction times for the semantically anomalous words in each text-language condition. Thus, within-language priming $=-\mathrm{S} /+\mathrm{L}-+\mathrm{S} /+\mathrm{L}$, and between-language priming $=-\mathrm{S} /-\mathrm{L}-+\mathrm{S} /-\mathrm{L}$.

In the present experiments, we have departed from other studies of bilingual language processing in two respects. First of all, most bilingual language studies have used lexical decision, which may be susceptible to postlexical search strategies (Balota \& Lorch, 1986). This is what led Altarriba (1991) to create low word-nonword and relatedness ratios to minimize expectancies. To avoid some of these problems, the current experiment used cross-modal naming (i.e., time required to pronounce a visual word in an auditory context). Naming is thought to provide a deeper and less strategic measure of lexical access; whether or not this is the case, it is certainly true that cross-modal naming produces faster latencies than lexical decision. Second, most studies have used minimal semantic contexts (i.e., word pairs). In fact, we are aware of only one study to date that has used sentence stimuli to investigate the nature of bilingual language processing (Altarriba, Kroll, Sholl, \& Rayner, in press). Although Altarriba et al. (in press) did not directly investigate sentence priming, their results reveal that high-constraint sentences can lead to slower reaction times for high-frequency words in the other language. That is, participants showed inhibition of the semantically congruent word because of lexical violations. This suggests that there may be some fast form of inhibition that serves to dampen cross-language priming in sentence contexts. A pilot study with the mixed design described above (Hernandez, 1992) revealed a significant main effect of semantic congruence $(-S$ vs. $+S)$, together with a significant Semantic $\times$ Linguistic interaction (see Figure 1). Planned comparisons showed that there was a significant semantic-congruency effect when both auditory and visual languages matched. When the test and target language were mismatched, bilinguals were equally slow for the $+S$ and $-S$ conditions. In other words, we found only within-language priming.

The results in Hernandez (1992) seem to fit easily within a lexical-postlexical framework. As was stated earlier, this view holds that within-language priming is intralexical and that cross-language priming is postlexical. In the mixed design, the target language was very unpredictable. There was no opportunity to engage in strategies. Thus, individuals were unable to consciously translate from one lexicon to another. This supports a dual-lexicon view in which words are represented separately. The present experiments explored this hypothesis further by expanding on the work by Hernandez.

First, we manipulated participants' expectancies by presenting both the original mixed design (in which individuals could not predict the language in which target words would occur) and a blocked design (in which target words always matched or always did not match the text language). The assumptions here are similar to those in word-level priming studies that manipulate the proportion of related words. Specifically, we assume that the mixed design (Experiment 1A) minimizes a person's ability to predict the upcoming language of the stimuli. If cross-language priming is subject to postlexical strategies, it should not appear when the target language is unpredictable. The blocked design (Experiment 1B) increases predictability and thus increases the likelihood of cross-language sentence priming. We suggest that the comparison of the presence or absence of cross-language priming in the blocked design with the presence or absence of cross-language priming may serve to ellucidate whether this effect is subject to strategic processing.

Second, participants were tested in both the mixed design (Experiment 2A) and the blocked design (Experiment 2B) with visually degraded targets (i.e., asterisks were placed

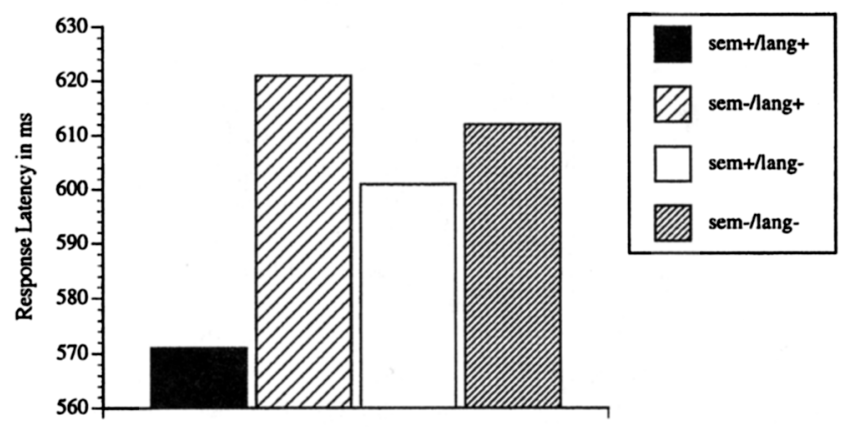

Figure 1. Semantic $\times$ Linguistic interaction for bilinguals in the cross-modal paradigm (adapted from Hernandez, 1992). Sem + and sem - = semantically congruent and incongruent, respectively; lang + and lang- = linguistically congruent and incongruent, respectively. 
before and after each letter). The point of the visualdegradation manipulation was to slow down the bottom-up word-recognition process, which would permit top-down sentential context more time to build up (Meyer et al., 1975; Stanovich \& West, 1983). If within-language priming is lexical, then we should see an increase in within-language priming under visual degradation (relative to normal viewing); conversely, if cross-language priming is controlled, then there should be no increase in priming under visual degradation.

Finally, two additional experiments were conducted to explore the effects of timing on the two priming types. In Experiment $3 \mathrm{~A}$, responses were artificially delayed in the mixed design; if cross-language priming does not appear in this design under normal conditions, it may emerge when participants are given time to consider their responses (i.e., a postlexical effect). If lexical and postlexical priming are staged processes, then we should expect to see an additive increase in within-language priming as well. In Experiment 3B, responses were obtained under speeded conditions in the blocked design. If cross-language priming is a postlexical effect, then it may disappear (even in the blocked design) when quick responses are required. A summary of predictions can be found in Table 1.

\section{Bilingual Cross-Modal Word Pronunciation}

\section{General Method}

Pretest materials. A set of questionnaires was used to obtain information about individuals' family handedness and language history. The language-history questionnaire asked questions pertaining to the nature of participants' acquisition of up to four languages as well as to their present use of these languages. A copy of the questionnaire can be found in Liu, Bates, and $\mathrm{Li}$ (1992).

Test materials and design. The materials in this task consisted of 22 seven- to eight-sentence texts chosen from third-grade-level textbooks. The passages were chosen to address a number of culturally neutral topics (i.e., animals, space, firefighters, etc.). These texts were originally in Spanish and were translated to English. In the mixed design, 15 texts were used. An additional 7 texts were added for the blocked design to ensure that no block was shorter than 4 texts. Totals of 136 and 104 words were extracted for the blocked design and the mixed design, respectively. There were between six and eight words for every text (approximately one word per sentence). The words that were extracted from the texts were replaced with words that were in one of four conditions. These words were semantically and linguistically congruent $(+S /+L)$, semantically congruent but linguistically incongruent $(+S /-L)$, semantically incongruent but linguistically congruent $(-S /+L)$, or semantically and linguistically incongruent $(-S /-L)$. In the blocked design, there were 17 items per cell, and in the mixed design, there were 13 items per cell. All of the targets were open-class words (i.e., nouns, adjectives, and verbs). Of these target items, only three adjectives and one verb were used as target words. The rest of the target items were nouns. Incongruent conditions were created by choosing a word that was of the same form class and that was of the same length (number of syllables) and frequency as the target word or its translation. An example of the stimuli can be seen in the appendix. For example, the word snakes was substituted for lights so that these would match on frequency and length. In addition, the word milagro was substituted to match trafico in length and frequency. We should point out that English and Spanish words were not (and cannot be) balanced for length, because Spanish words are significantly longer on average. We might expect this to lead to significantly longer word- onset latencies in Spanish, although (as we show) there is surprisingly little evidence for a cross-linguistic difference of this kind.

The English word targets were all balanced for frequency of occurrence by using Kučera and Francis's (1967) norms. In Spanish, there is no comprehensive frequency list (Juilland \& ChangRodriguez, 1964), and thus there is no means of assuring a frequency balance over conditions. However, there were no obvious discrepancies in the nature of target words or their substitutes in either language condition. The texts were divided into two sets such that no person saw the same text across sessions. Although the stimuli where not randomized across individuals (one cannot randomize sentences in a discourse paradigm), the conditions that appeared were randomized so that participants could not predict which of the four conditions would appear.

Procedure. Bilingual participants were tested individually by a bilingual research assistant in two sessions, one for each language. The language of the sessions was determined by the auditory language in which the sentence contexts were presented. During any particular session the participants were exposed to only one auditory language (by the experimenter and the computer) and were instructed to speak the language of the session to communicate with the experimenter. The first session and the second session were separated by at least a day.

The participants were told that they would be hearing a set of texts about which they would have to answer a multiple-choice question. Thus, they should pay attention to the content of the passage. In addition, they were advised that during the text the recording would stop and a word would appear on the screen. Individuals were told that they should pronounce the word as quickly and accurately as possible. They were informed that some words would be in Spanish and others would be in English and that these words might not fit with the text. The texts were presented auditorially. At a predetermined point during the text, the sound would stop and a visual word was immediately (i.e., $\mathrm{SOA}=0$ ) presented on the computer screen. The visual targets were presented immediately after the prior auditory word. A response window of $1 \mathrm{~s}$ was given. If the participant responded before $1 \mathrm{~s}$ had passed, then the text continued. If after $1 \mathrm{~s}$ had elapsed no response had been recorded, the word would come off the screen and the auditory text would resume. At the end of the text, a question would appear on the screen. These questions were about the text that had just been presented and served as a rough measure of the level of comprehension. Once the question was answered, the next passage would begin.

Both visual and auditory stimuli for the bilingual cross-modal paradigms were presented by a Zenith IBM AT compatible computer. The auditory stimuli were played through a set of Realistic speakers. The visual stimuli were presented on an Amdek 310a monochrome monitor.

For any particular session, the auditory language was held constant, and the visual stimuli were presented either in the same or the other language. In the mixed design (i.e., Experiments 1A, 2A, and 3A), the visual language was unpredictable. Individuals saw words in both languages in both sessions. In the blocked design (i.e., Experiments $1 \mathrm{~B}, 2 \mathrm{~B}$, and $3 \mathrm{~B}$ ), the visual language was much more predictable. To accomplish this, each session was separated into two blocks, which were separated by a short break. For each block, participants were shown either within- or between-language stimuli only.

In Experiment 2, the participants were shown the mixed and blocked design in exactly the same manner as in Experiment 1 except that all of the words were degraded by adding asterisks before and after each letter. In Experiment 3A, individuals were shown the same stimuli as in Experiment 1A. However, participants were instructed to wait for a visual cue (a set of parentheses that appeared after $500 \mathrm{~ms}$ ) before they initiated their response. In Experiment 3B, individuals were shown the same stimuli as in Experiment 1B except that the word 
was replaced by a mask after $500 \mathrm{~ms}$. This was done to speed responses.

\section{Experiment 1A: Cross-Modal Word Pronunciation in a Mixed Design}

\section{Method}

The participants were 15 University of California, San Diego undergraduates recruited through announcements made on campus and through word of mouth. The mean age of the group was 19.9 years $(S D=2.57)$. This group had spent 14.6 years speaking English and 19.5 years speaking Spanish-an experience characteristic of SpanishEnglish bilinguals in Southern California. One of the 20 participants rated himself as a native English speaker, although he did not differ from the other participants on any language-history measure (see below). The rest considered themselves native Spanish speakers. Those tested were either about to enroll in college or were currently enrolled in college. Participants were given both an English-bilingual version and the Spanish-bilingual version of the experiment in two separate counterbalanced sessions. Each individual was paid $\mathbf{\$ 5}$ for each hour of participation. Each participant took part in only one of the experiments. Thus, experiment type was a between-subjects manipulation.

\section{Results and Discussion}

Error rates. The error rate overall for this experiment was lower than $2 \%$ and was not subjected to any other analyses. Errors were removed from the reaction-time data.

Difference scores. Difference scores were computed by subtracting reaction times for semantically congruent $(+S)$ words from reaction times for semantically incongruent $(-S)$ words. For each participant, a within-language priming score was computed by subtracting the $+\mathrm{S} /+\mathrm{L}$ from the $-\mathrm{S} /+\mathrm{L}$ condition; a between-language priming score was computed by subtracting the $+\mathrm{S} /-\mathrm{L}$ condition from the $-\mathrm{S} /-\mathrm{L}$ condition. These scores were calculated separately for each language (i.e., Spanish text vs. English text). These priming scores were entered into a 2 (language of the auditory text) $\times 2$ (within-vs. between-language priming) within-subjects factorial analysis of variance (ANOVA). This analysis yielded a significant main effect of type of linguistic congruence, $F(1,14)=10.793, p<$ .005 , in which within-language priming was significantly larger than cross-language priming. No other effects reached significance. See Table 2 for a summary of results.

Response latencies across experimental conditions. In all of the experiments mentioned, $F_{1}$ refers to analyses over subjects, and $F_{2}$ refers to analyses over items. An item was defined as every word that was presented to a participant. A betweenitems ANOVA was used for all items analyses. The response latencies for this experiment were entered into a 2 (text language) $\times 2$ (semantic congruence) $\times 2$ (linguistic congruence) within-subjects factorial design. There were significant main effects of text language, $F_{1}(1,14)=4.425, p<.05$, $M S E=20,720.07 ; F_{2}(1,200)=20.280, p<.000, M S E=$ $5,929.15$, and semantic congruence, $F_{1}(1,14)=11.520, p<$ $.004, M S E=2,656.75 ; F_{2}(1,200)=5.886, p<.05, M S E=$ $5,929.15$. Individuals were faster for semantically congruent words $(655 \mathrm{~ms})$ than for semantically incongruent words (688 $\mathrm{ms}$ ), and they were faster when English was the text language (644 ms) than when Spanish was the text language $(698 \mathrm{~ms})$. There was also a significant Semantic $\times$ Linguistic Congruence interaction, $F_{1}(1,14)=10.790, p<.005, M S E=962.24 ; F_{2}(1$, $200)=1.980, p<.161, M S E=5,929.15$. The interaction is illustrated in Figure 2A.

A modified Bonferroni procedure was used to compare the four conditions in Figure 2A. The family-wise error rate was set at 0.05 , and the alpha level for any particular test was set at

Table 2

Mean Reaction Times (RTs) and Error Rates (in Percentages) for Bilingual Participants in Experiment 1

\begin{tabular}{|c|c|c|c|c|c|c|c|}
\hline \multirow{2}{*}{$\begin{array}{c}\text { Auditory and } \\
\text { visual language }\end{array}$} & \multicolumn{2}{|c|}{ SEM+ } & \multicolumn{2}{|c|}{ SEM- } & \multicolumn{2}{|c|}{$M$} & \multirow[b]{2}{*}{ Priming } \\
\hline & $\overline{\mathrm{RT}}$ & $\%$ error & $\overline{\mathbf{R T}}$ & $\%$ error & $\overline{\text { RT }}$ & $\%$ error & \\
\hline \multicolumn{8}{|c|}{ Experiment 1A: Mixed normal } \\
\hline \multicolumn{8}{|l|}{ English } \\
\hline English (lang+) & 612 & 0.24 & 660 & 0.88 & 636 & 0.56 & $+48^{* *}$ \\
\hline Spanish (lang-) & 645 & 0.96 & 658 & 0.88 & 652 & 0.92 & $+13^{*}$ \\
\hline \multicolumn{8}{|l|}{ Spanish } \\
\hline Spanish (lang + ) & 676 & 1.40 & 728 & 1.76 & 702 & 1.58 & $+52^{* *}$ \\
\hline English (lang-) & 685 & 1.20 & 704 & 1.76 & 695 & 1.48 & $+19^{*}$ \\
\hline \multicolumn{8}{|c|}{ Experiment 1B: Blocked normal } \\
\hline \multicolumn{8}{|l|}{ English } \\
\hline English (lang+) & 663 & 0.00 & 724 & 1.20 & 694 & 0.60 & $+61^{* *}$ \\
\hline Spanish (lang - ) & 674 & 2.98 & 712 & 0.99 & 693 & 1.99 & $+38^{* *}$ \\
\hline \multicolumn{8}{|l|}{ Spanish } \\
\hline Spanish (lang+) & 633 & 0.79 & 667 & 1.19 & 650 & 0.99 & $+34^{* *}$ \\
\hline English (lang-) & 653 & 0.60 & 690 & 0.99 & 672 & 0.80 & $+37^{* *}$ \\
\hline
\end{tabular}

Note. Statistical significance was calculated by making planned comparisons of individual data points. This procedure involves the use of the mean square error of the entire interaction and is more conservative than one-way analyses of variance or $t$ tests. Lang + and lang - $=$ linguistically congruent and incongruent, respectively; SEM + and SEM- = semantically congruent and incongruent, respectively. ${ }^{*} p=\mathrm{ns} . \quad{ }^{* *} p<.05$. 
A: Experiment 1A: Mixed design under normal viewing conditions

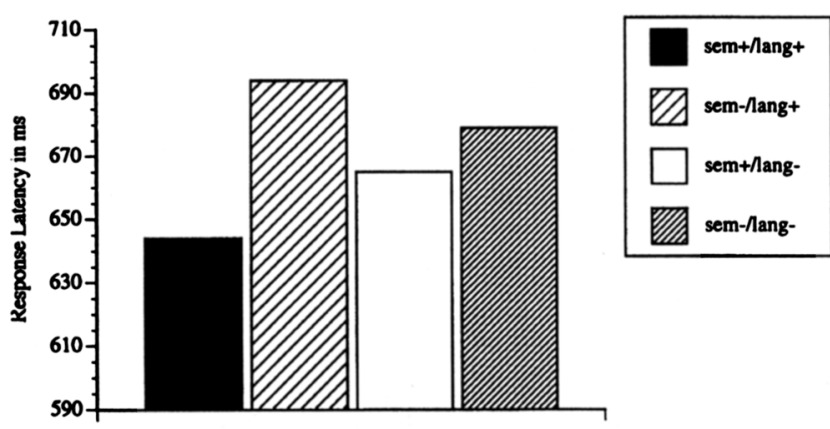

B: Experiment 1B: Blocked design under normal viewing conditions

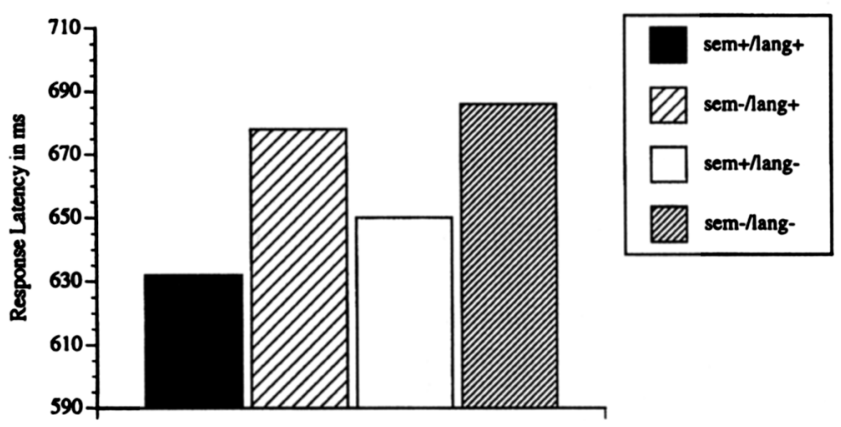

Figure 2. Semantic $\times$ Linguistic interactions in Experiment 1. Sem + and sem- = semantically congruent and incongruent, respectively; lang + and lang $-=$ linguistically congruent and incongruent, respectively.

.01. Results show that the $+\mathrm{S} /+\mathrm{L}$ condition was significantly faster than each of the other three conditions, which did not differ significantly from one another. In accord with the original study by Hernandez (1992), these results again show significant priming within language and no priming across the language boundary. However, it is important to note that the Semantic $\times$ Linguistic interaction was significant across subjects only.

Findings from the present experiment replicate Hernandez (1992) and are largely consistent with a dual-process account of within- and between-language priming. Specifically, when participants are unable to predict the target language, only within-language priming appears. However, two aspects of these findings are problematic for the two-stage account. First, reaction times were not slower overall for the betweenlanguage condition (i.e., there was no main effect of linguistic congruity). If individuals must rely on some kind of postlexical translation process to access and produce a cross-language word, we would have expected some kind of difference in reaction time. Second, Figure 2A (like Figure 1) suggests that participants may have the beginnings of cross-language semantic priming even though the effect is not reliable at the group level. Increasing target-language predictability through the use of a blocking variable should increase the likelihood that cross-language priming will appear. In addition, an increase in predictability should lead to an even bigger increase in the size of within-language priming, based on the assumption that lexical and postlexical priming are additive (see Table 1).

\section{Experiment 1B: Cross-Modal Word Pronunciation in a Blocked Design}

\section{Method}

The participants were 15 University of California, San Diego undergraduates recruited through announcements made on campus and through word of mouth. The mean age of the group was 20.2 years $(S D=2.30)$. This group had spent 13.6 years speaking English and 19.9 years speaking Spanish. All of the participants considered themselves native Spanish speakers and were currently enrolled in college. As in Experiment 1A, individuals were given both an Englishbilingual version and the Spanish-bilingual version of the experiment in two separate sessions. The sessions were always conducted in the text language (including conversation before the experiment). Each participant was paid $\$ 5$ for each hour of participation.

\section{Results and Discussion}

Error rate. The error rate was below $1 \%$. No further analyses were conducted. The errors were removed from the reaction-time data.

Difference scores. Priming scores were calculated with the same method described in Experiment 1A. These scores were placed in a 2 (text language) $\times 2$ (between-within) ANOVA, which yielded no significant main effects and no interaction. In other words, in contrast with Experiment 1A, equivalent priming was obtained across the within- and between-language conditions $(M=36 \mathrm{~ms})$. Results are summarized in Table 2 (where Experiments $1 \mathrm{~A}$ and 1B can be compared). The emergence of cross-language priming under blocked conditions is consistent with the idea that this form of priming is a postlexical, expectancy-driven effect (see predictions in Table 1). However, the within-language priming effect should have been even larger than the cross-language priming effect because of the additivity of automatic and controlled priming. This was not observed.

Response latencies across experimental conditions. The response latencies for this experiment were entered into a 2 (text language) $\times 2$ (semantic congruence) $\times 2$ (linguistic congruence) within-subjects factorial design. There was a main effect of semantic congruence, $F_{1}(1,14)=96.913, p<.01, M S E=$ $524.63 ; F_{2}(1,280)=16.368, p<.01, M S E=6,352.62$. The Linguistic $\times$ Semantic interaction is illustrated in Figure 2B.

The main effect of semantic congruence shows that participants were faster for semantically congruent words $(648 \mathrm{~ms})$ than for semantically incongruent words $(684 \mathrm{~ms})$, which corresponds to our results above for priming-difference scores. The main effect of text language reflects a strange reversal of the effect in Experiment 1A. In that experiment, individuals were faster when listening to English. In the present experiment, responses across items were faster when participants listened to Spanish $(660 \mathrm{~ms})$ than when they listened to English $(693 \mathrm{~ms})$. In addition, the text-language effect interacted with linguistic condition across items. That is, for English 
auditory texts, reaction times across items were almost identical for Spanish and English targets; for Spanish auditory texts, reaction times across items were faster for English than for Spanish targets. This is exactly the opposite of what we would expect if switching languages requires some kind of postlexical translation. Note, however, that these effects did not interact with semantic condition across subjects or items (i.e., they did not interact with priming).

A set of planned comparisons were run in exactly the same way as in Experiment $1 \mathrm{~A}$. The $+\mathrm{S} /+\mathrm{L}$ was faster than $-\mathrm{S} /+\mathrm{L}$, $F(1,14)=49.090, p<.001, M S E=732.86$, and $+\mathrm{S} /-\mathrm{L}$ was faster than $-\mathrm{S} /-\mathrm{L}, F(1,14)=30.770, p<.001, M S E=$ 732.86. This implies that semantic congruence had a significant effect in both linguistic conditions, in contrast with the mixed design in Experiment 1A.

The major result from Experiment $1 \mathrm{~B}$ is clear. Blocking permitted cross-language priming to emerge at levels equivalent to those obtained in the within-language condition. It appears that people's expectancies were driving the difference in priming between our mixed and blocked design. As mentioned before, expectancy has been found to play a large role in the lexical-decision literature (Tweedy, Lapinski, \& Schvaneveldt, 1977). Specifically, it has been found that a large proportion of related-word pairs leads to a significant increase in the amount of priming. Participants in the mixed condition in Experiment 1A could not be sure whether they would have to pronounce a Spanish or an English word. Hence, we see only lexical priming, and that occurs only in the withinlanguage condition (cf. Grainger \& Beauvillain, 1988). In the blocked condition in Experiment 1B, individuals did know what text language to expect. Hence, they could add an expectancy-based, strategic form of priming, which creates the cross-language semantic-priming effect.

Although our results for cross-language priming are largely compatible with predictions based on the traditional model (Table 1), we did not obtain evidence for additivity of lexical and postlexical effects in the within-language priming results. This may mean that the lexical component of within-language priming is so small (and perhaps so short lived) that it is completely masked by the expectancy-driven effects observed in the blocked design. One way to test this hypothesis would be to slow bottom-up word recognition, thereby allowing more time for lexical context effects to grow. If cross-language priming is purely strategic, then delaying lexical access should not increase its size. If within-language priming involves a combination of lexical and postlexical effects, then visual degradation should reveal larger effects than we found in the present experiments. Specifically, we should find an increase in lexical effects in the mixed-degraded condition (Experiment 2A) and an even larger combination of lexical and postlexical effects in the blocked-degraded condition (Experiment 2B).

\section{Experiment 2A: Cross-Modal Word Pronunciation in a Mixed Design With Visually Degraded Stimuli}

\section{Method}

The participants were 15 University of California, San Diego undergraduates recruited through announcements made on campus and through word of mouth. The mean age of the group was 22.2 years $(S D=2.52)$. This group had spent an average of 17 years speaking English and 20 years speaking Spanish. Three of the 20 participants rated themselves as native English speakers but did not differ noticeably on any of the language-questionnaire items from the rest of the participants, who considered themselves native Spanish speakers. All of the participants were either about to enroll in college or were currently enrolled in college. As in Experiment 2A, individuals were given both an English-bilingual version and the Spanish-bilingual version of the experiment in two separate sessions. Each participant was paid $\$ 5$ for each hour of participation.

\section{Results and Discussion}

Error rates. The error rate overall for this experiment was less than $1 \%$ and was not subjected to further analyses.

Difference scores. As in previous experiments, priming scores were obtained by subtracting reaction times for semantically congruous conditions from those for semantically incongruous conditions within each language and priming condition. A 2 (text language) $\times 2$ (within-between) ANOVA on these priming scores revealed a significant effect of type of linguistic congruence, $F(1,14)=10.333, p<.01, M S E=1,989.21$, and a significant main effect of text language, $F(1,14)=10.333, p<$ $.0, M S E=1,276.20$, but no significant interaction. The textlanguage effect reflects larger priming scores when listening to English $(M=56 \mathrm{~ms})$ than Spanish $(M=21 \mathrm{~ms})$-a difference that we did not observe under normal reading conditions in either the mixed or the blocked design. The priming-condition effect reflects larger priming effects in the within-language condition $(M=65 \mathrm{~ms})$ than in the between-language conditions $(M=12 \mathrm{~ms})$, which is similar to our findings in Experiment 1A. Results are summarized in Table 3.

Reaction times across experimental conditions. The raw response latencies were entered into a 2 (language) $\times 2$ (semantic congruence) $\times 2$ (linguistic congruence) ANOVA with all variables within subjects. There was a significant effect of semantic congruence, $F_{1}(1,14)=24.440, p<.001, M S E=$ $2,091.41 ; F_{2}(1,200)=15.030, p<.001, M S E=5,509.09$, reflecting faster reaction times for semantically congruent words than for incongruent words ( $781 \mathrm{~ms}$ vs. $822 \mathrm{~ms}$ ). There was also a significant Semantic $\times$ Linguistic interaction, $F_{1}(1$, 14) $=12.725, p<.003, M S E=1,378.09 ; F_{2}(1,200)=6.74$, $p<.01, M S E=5,509.09$, as well as a Text Language $\times$ Semantic interaction, $F_{1}(1,14)=12.252, p<.003, M S E=$ 994.61; $F_{2}(1,200)=2.351, p<.127, M S E=5,509.09$. The Text Language $\times$ Semantic interaction reflects greater priming (i.e., a greater difference between $+S$ and $-S$ ) when individuals were listening to English. The Semantic $\times$ Linguistic interaction shows the same pattern as the one found in Experiment 1A. That is, participants showed significant withinlanguage priming and minimal cross-language priming. The Semantic $\times$ Linguistic interaction is illustrated in Figure $3 \mathrm{~A}$.

As in Experiment 1A, the modified Bonferroni procedure was used to test the significance of the planned comparisons in the Semantic $\times$ Linguistic interaction with a family-wise error rate set at $\mathbf{0 . 0 5}$, and the alpha level for any particular test set at .01. The $+\mathrm{S} /+\mathrm{L}$ condition was significantly faster than the $-\mathrm{S} /+\mathrm{L}$ condition, $F(1,28)=46.000, p<.001, M S E=$ $1,378.09$, which confirms the presence of large and significant 
Table 3

Mean Reaction Times (RTs) and Error Rates (in Percentages) for Bilingual Participants in Experiment 2

\begin{tabular}{|c|c|c|c|c|c|c|c|}
\hline \multirow{2}{*}{$\begin{array}{l}\text { Auditory and } \\
\text { visual language }\end{array}$} & \multicolumn{2}{|c|}{ SEM+ } & \multicolumn{2}{|c|}{ SEM- } & \multicolumn{2}{|c|}{$M$} & \multirow[b]{2}{*}{ Priming } \\
\hline & $\overline{\mathrm{RT}}$ & $\%$ error & $\overline{\mathrm{RT}}$ & $\%$ error & $\overline{\mathrm{RT}}$ & $\%$ error & \\
\hline \multicolumn{8}{|c|}{ Experiment 2A: Mixed degraded } \\
\hline \multicolumn{8}{|l|}{ English } \\
\hline English (lang+) & 754 & 0.24 & 834 & 1.90 & 794 & 1.07 & $+80^{* * *}$ \\
\hline Spanish (lang-) & 767 & 0.95 & 809 & 1.07 & 788 & 1.01 & $+42^{* *}$ \\
\hline \multicolumn{8}{|l|}{ Spanish } \\
\hline Spanish (lang +) & 789 & 0.12 & 840 & 1.19 & 815 & 0.66 & $+51^{* *}$ \\
\hline English (lang-) & 813 & 0.71 & 805 & 0.83 & 809 & 0.77 & $-8^{*}$ \\
\hline \multicolumn{8}{|c|}{ Experiment 2B: Blocked degraded } \\
\hline \multicolumn{8}{|l|}{ English } \\
\hline English (lang+) & 729 & 0.86 & 820 & 1.17 & 775 & 1.10 & $+91^{* * *}$ \\
\hline Spanish (lang-) & 780 & 1.21 & 825 & 0.93 & 803 & 1.07 & $+45^{* *}$ \\
\hline \multicolumn{8}{|l|}{ Spanish } \\
\hline Spanish (lang +) & 740 & 0.35 & 777 & 1.54 & 759 & 0.95 & $+37^{* *}$ \\
\hline English (lang-) & 777 & 0.52 & 824 & 0.76 & 801 & 0.64 & $+47^{* *}$ \\
\hline
\end{tabular}

Note. Statistical significance was calculated by making planned comparisons of individual data points. This procedure involves the use of the mean square error of the entire interaction and is more conservative than using one-way analyses of variance or $t$ tests. Lang + and lang $-=$ linguistically congruent and incongruent, respectively; SEM + and SEM- = semantically congruent and incongruent, respectively. ${ }^{*} p=n s .{ }^{* *} p<.05 .{ }^{* * *} p<.01$

priming effects in the within-language condition. The $+\mathrm{S} /-\mathrm{L}$ condition was not significantly different from $-\mathrm{S} /-\mathrm{L}$, which means that there was no significant priming effect in the cross-language condition, although there was a trend in the direction of cross-language priming, $F(1,28)=3.140, p<.10$, $M S E=1,378.09$.

Notice also that Experiment $2 \mathrm{~A}$ produced a main effect of text (auditory) language on priming-difference scores, with more priming in English (56 ms) than in Spanish (21 ms). This reflects greater within-language priming in English $(80 \mathrm{~ms}$ in English vs. $50 \mathrm{~ms}$ in Spanish). More important for our purposes here, it appears that between-language priming was starting to emerge when individuals were listening to English and reading degraded Spanish words, $+32 \mathrm{~ms} ; F(1,28)=$ $25.790, p<.001, M S E=513.02$, whereas it was entirely absent when individuals were listening to Spanish and reading degraded English words, $-8 \mathrm{~ms} ; F(1,28)<1.00, p<n s, M S E=$ 513.02. Thus, an account of bilingual priming must take into account the "inequality" of one of the languages. We return to this point later.

Results from the mixed, visually degraded design (Experiment $2 \mathrm{~A}$ ) are similar in key respects to our results in the mixed design under normal viewing conditions (Experiment 1A). That is, semantic priming was only observed in the withinlanguage condition (at least for Spanish). This suggests that cross-language priming is postlexical. However, we did not find the expected main effect of linguistic congruence (i.e., a general slowing when words must be pronounced following a language switch). In addition, it does not appear that visual degradation increased the overall magnitude of withinlanguage priming effects, despite a $130-\mathrm{ms}$ slowdown in average reaction time (i.e., a mean reaction time of $671 \mathrm{~ms}$ in Experiment $1 \mathrm{~A}$ vs. $804 \mathrm{~ms}$ in Experiment 2A). Collapsed across conditions, the average priming score in Experiment $2 \mathrm{~A}$
A: Experiment 1A: Mixed design under normal viewing conditions

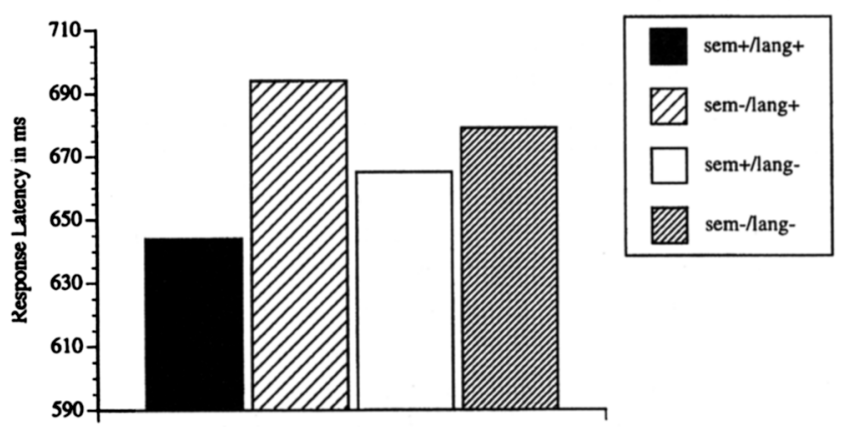

B: Experiment 1B: Blocked design under normal viewing conditions

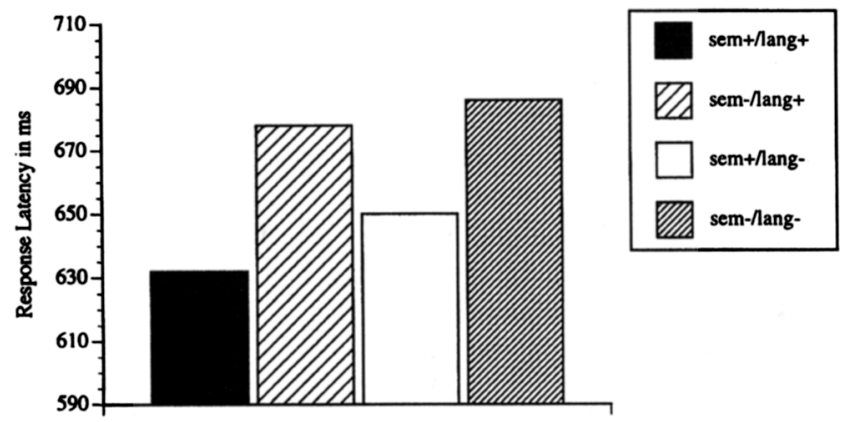

Figure 3. Semantic $\times$ Linguistic interactions in Experiment 2. Sem + and sem- = semantically congruent and incongruent, respectively; lang + and lang $-=$ linguistically congruent and incongruent, respectively. 
was $41.3 \mathrm{~ms}$ compared with an average of $33 \mathrm{~ms}$ in Experiment 1A. Hence, there is no reliable evidence that visual degradation results in a swelling of within-language priming effects, although results are in the predicted direction. A direct statistical comparison across Experiments 1 and 2 is presented later.

Experiment 2B: Cross-Modal Word Pronunciation in a Blocked Design With Visually Degraded Stimuli

\section{Method}

The participants were 15 University of California, San Diego undergraduates recruited through announcements made on campus and through word of mouth. The mean age of the group was 22.3 years $(S D=2.62)$. This group had spent 18.6 years speaking English and 21.5 years speaking Spanish. Four of the participants considered both Spanish and English to be their native language. One individual considered English to be his native language, and the rest considered Spanish to be their native language. All participants were currently enrolled in college. As in Experiment 1B, participants were given both an English-bilingual version and the Spanish-bilingual version of the experiment in two separate sessions. Each individual was paid $\$ 5$ for each hour of participation.

\section{Results and Discussion}

Error rate. The error rate was below $1 \%$ and was not subjected to further analyses.

Difference scores. Difference scores were computed with the same method used in previous experiments and were entered into a 2 (text language) $\times 2$ (within-between) ANOVA. This yielded a significant effect of linguistic congruence across individuals, $F(1,14)=5.320, p<.037, M S E=930.22$, with bilinguals showing larger priming within languages than between languages, as in Experiments $1 \mathrm{~A}$ and $2 \mathrm{~A}$ but not as in the blocked design in Experiment 1B. Hence, we finally have evidence for additivity of lexical and postlexical priming in the within-language condition under high expectancy.

Across individuals, there was a trend toward a main effect of text language, $F(1,14)=4.470, p<.053, M S E=2,216.17$, and a trend toward a Text Language $\times$ Condition interaction, $F(1$, 14) $=4.380, p<.055, M S E=2,620.09$. Participants showed larger priming effects when they had to read English words, regardless of the text language. Specifically, bilingual individuals showed more priming in the within-language condition than in the between-language condition when they were listening to English (90 ms for English words in English text vs. $45 \mathrm{~ms}$ for Spanish words in English text), $F(1,14)=5.800, p<$ $.03, M S E=2,620.09$. When individuals listened to Spanish there was no difference between within- and betweenlanguage priming. Because trends were not reliable $(p<.06)$, we should be cautious in interpreting them further. However, this does mean that the additivity of within- and betweenlanguage priming described above may hold only for English texts. See Table 3 for a summary of results.

Response times across experimental conditions. The raw response latencies were placed into a 2 (language) $\times 2$ (semantic congruence) $\times 2$ (linguistic congruence) withinsubjects ANOVA. There was a significant main effect of semantic congruence, $F_{1}(1,14)=65.790, p<.0001, M S E=$ $1,379.46 ; F_{2}(1,280)=41.510, p<.000, M S E=5,153.57$, reflecting faster reaction times in the semantically congruent condition. There was also a main effect of linguistic congruence, $F_{1}(1,14)=25.220, p<.0001, M S E=1,456.77 ; F_{2}(1$, $280)=14.420, p<.000, M S E=5,153.57$, with faster reaction times in the within-language condition. This is the first time the predicted within-between difference has been seen on raw reaction times (see Table 1 ).

The Semantic $\times$ Linguistic interaction was significant, $F_{1}(1$, $14)=5.320, p<.037, M S E=464.91 ; F_{2}(1,280)=1.680, p<$ $.195, M S E=5,153.56$. As noted above, this interaction (illustrated in Figure 3B) reflects greater priming in the within-language condition. The Text Language $\times$ Semantic interaction and the Text Language $\times$ Semantic $\times$ Linguistic interaction were also significant, $F_{1}(1,14)=4.47, p<.053$, $M S E=1,108.06 ; F_{2}(1,280)=1.68, p<.2, M S E=5,153.57$, and $F_{1}(1,14)=4.38, p<.055, M S E=1,310.19 ; F_{2}(1,280)=$ $3.31, p<.07, M S E=5,153.57$, respectively, reflecting the trend toward greater within-language priming in English that we just described. Results are summarized in Table 3. The Semantic $\times$ Linguistic interaction is illustrated in Figure 3B.

Once again, a set of planned comparisons was conducted to explore the Semantic $\times$ Linguistic interaction. Results confirm the presence of semantic priming in both linguistic conditions: $+\mathrm{S} /+\mathrm{L}<-\mathrm{S} /+\mathrm{L}, F(1,28)=132.040, p<.001, M S E=$ 464.91 , and $+\mathrm{S} /-\mathrm{L}<-\mathrm{S} /-\mathrm{L}, F(1,28)=68.410, p<.0001$, $M S E=464.91$. This is similar to results for the blocked design under normal viewing conditions (Experiment 1B). However, the within- and across-language priming effects differ in magnitude under visual degradation. That is, within-language priming is larger than cross-language priming under visually degraded conditions.

Experiment $2 \mathrm{~B}$ shows that the blocked design allows bilinguals to prime both within and between languages, even when stimuli are presented under visual degradation. However, visual degradation does change some of the effects in the blocked design compared with the same design under normal viewing conditions (Experiment 1B). In blocked normal conditions, there was absolutely no reliable difference in the size of priming within and across languages (and hence no evidence for additivity of lexical and postlexical priming in the within condition). In blocked but visually degraded conditions, withinlanguage priming was larger overall and was particularly large when participants were reading English words in English text. We had predicted that delays in the buildup of orthographic information would not increase the size of cross-language priming. Findings were consistent with this prediction, supporting a postlexical account of cross-language priming. We also predicted that visual degradation would increase the size of within-language priming (relative to the normal viewing conditions in Experiment 1B) and that the predicted additivity between lexical and postlexical priming would emerge when the lexical-priming effect was allowed to grow because of visual degradation. Results are largely compatible with these predictions.

To confirm or disconfirm the interpretations that we have offered in four separate experiments, we conducted one final ANOVA on priming (difference scores) across the four experi- 
ments. (Because of variations in reaction time for Spanish and English within and across these experiments, we chose not to conduct a cross-experiment analysis on raw or adjusted reaction times.) This analysis required a $2 \times 2 \times 2 \times 2$ design within two levels each of text language, linguistic congruence, mixed versus blocked design, and normal versus visually degraded reading conditions. Results included a significant main effect of text language, $F(1,56)=9.290, p<.001$, $M S E=2,317.40$, with larger priming scores in English (52 ms) than Spanish ( $33 \mathrm{~ms}$ ). There was also a significant main effect of linguistic congruence, $F(1,56)=27.410, p<.001, M S E=$ $1,688.73$, with larger priming scores within languages (56 ms) than between languages $(29 \mathrm{~ms})$. The Experiment Type $\times$ Linguistic interaction can be seen in Figure 4.

There was no main effect of visual degradation on priming scores. The only significant effect of visual degradation was a Visual Condition $\times$ Text Language interaction, $F(1,56)=$ $5.117, p<.028, M S E=2,317.40$. Under visually degraded conditions, the difference in priming scores was greater in English (64 ms) than Spanish (31 ms); under normal viewing conditions, the difference between languages was much smaller (44 $\mathrm{ms}$ for English, $35 \mathrm{~ms}$ for Spanish). In the absence of a significant interaction between degradation and linguistic congruence, some of our earlier interpretations have to be constrained (i.e., degradation does not necessarily lead to a swelling of within-language priming effects). Furthermore, the absence of a three-way interaction of degradation, linguistic congruence, and the mixed-blocked manipulation means that we do not have firm evidence that the predicted additivity between lexical and postlexical effects on within-language priming is released under degradation.

The most important effect for our purposes was a significant two-way interaction between linguistic congruence and the mixed-blocked manipulation. In the mixed condition, withinlanguage priming scores were significantly larger than betweenlanguage scores ( $57 \mathrm{~ms}$ vs. $16 \mathrm{~ms}$, respectively). In the blocked condition, results were in the same direction, but the difference was considerably smaller ( $55 \mathrm{~ms}$ within language, $41 \mathrm{~ms}$ between language). There was also a significant three-way interaction of linguistic congruence, text language, and the mixed-blocked manipulation, $F(1,56)=4.150, p<.046$,

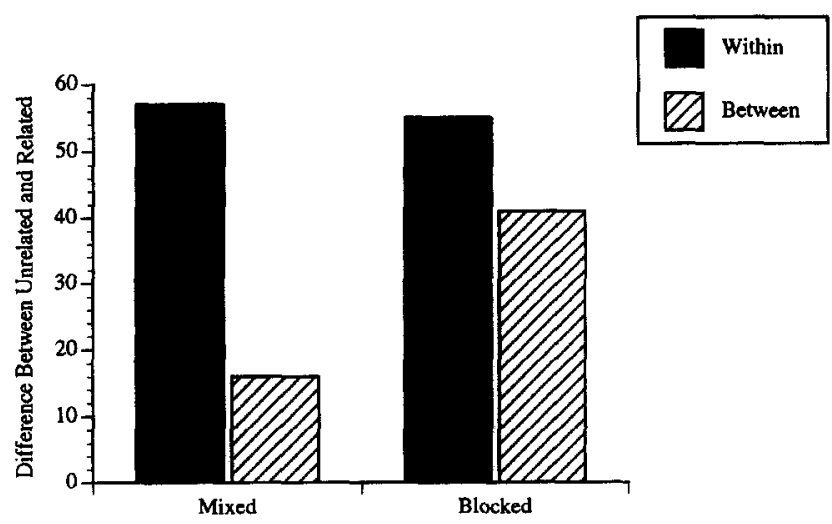

Figure 4. Experiment Type $\times$ Linguistic interaction for Experiments 1 and 2 combined.
$M S E=2,230.75$. The two-way interaction of linguistic congruence by mixed/blocked described earlier was in the same direction in both the English and Spanish text conditions. However, there were text-language differences in the magnitude of these effects. When individuals were listening to English, within-language priming was particularly large, especially in the blocked condition (mixed within $=64 \mathrm{~ms}$, blocked within $=75 \mathrm{~ms}$, mixed between $=27 \mathrm{~ms}$, blocked between $=41$ $\mathrm{ms}$ ). When participants were listening to Spanish, priming scores were particularly small in the between-language mixed condition (mixed within $=51 \mathrm{~ms}$, blocked within $=35 \mathrm{~ms}$, mixed between $=5 \mathrm{~ms}$, blocked between $=41 \mathrm{~ms}$ ). So our main conclusions do not vary qualitatively as a function of text language. However, we may conclude that the best priming condition (i.e., blocked within) is when listening to English and that the worst priming condition (i.e., mixed between) is when listening to Spanish. This suggests that our effects interact with basic differences in reading and listening proficiencydifferences that appear to favor English in these SpanishEnglish bilinguals. Even though Spanish is the first language for all those who were tested, they are currently living, working, and (above all) reading in an English environment, a factor which has some influence on our results. We return to this point later.

\section{Experiment 3A: Cross-Modal Word Pronunciation in a Mixed Design Using Delayed Naming}

\section{Method}

The participants were 15 University of California, San Diego undergraduates recruited through announcements made on campus and through word of mouth. The mean age of the group was 20.5 years $(S D=2.39)$. This group had spent 17.9 years speaking English and 18.9 years speaking Spanish. Three of the participants considered both Spanish and English to be their native language. Two of them considered English to be their native language, and the rest considered Spanish to be their native language. All participants were currently enrolled in college. As in Experiment 1A, participants were given both an English-bilingual version and the Spanish-bilingual version of the experiment in two separate sessions. Each individual was paid $\$ 5$ for each hour of participation.

\section{Results}

Error rate. The error rate was below $1 \%$ and was not subjected to further analyses.

Difference scores. Priming scores were calculated with the method described in Experiment 1A. These scores were placed in a 2 (text language) $\times 2$ (between-within) ANOVA, which yielded no significant main effects and no interaction. In other words, in contrast with Experiment $1 \mathrm{~A}$, equivalent priming was obtained across the within- and between-language conditions ( $M=36 \mathrm{~ms})$. Note also that there were no interactions with text language, in contrast with our findings under visual degradation. Results are summarized in Table 4.

Response times across experimental conditions. Reaction times for this experiment were calculated from the onset of the visual target. In other words, the reaction time included the $500 \mathrm{~ms}$ before the response cue. These response latencies were used for a 2 (language) $\times 2$ (semantic congruence) $\times 2$ 
Table 4

Mean Reaction Times (RTs) and Error Rates (in Percentages) for Bilingual Participants in Experiment 3

\begin{tabular}{|c|c|c|c|c|c|c|c|}
\hline \multirow{2}{*}{$\begin{array}{l}\text { Auditory and } \\
\text { visual language }\end{array}$} & \multicolumn{2}{|c|}{ SEM+ } & \multicolumn{2}{|c|}{ SEM- } & \multicolumn{2}{|c|}{$M$} & \multirow[b]{2}{*}{ Priming } \\
\hline & $\overline{\mathrm{RT}}$ & $\%$ error & $\overline{\mathrm{RT}}$ & $\%$ error & $\overline{\mathrm{RT}}$ & $\%$ error & \\
\hline \multicolumn{8}{|c|}{ Experiment 3A: Mixed delayed } \\
\hline \multicolumn{8}{|l|}{ English } \\
\hline English (lang +) & 771 & 0.09 & 815 & 0.13 & 793 & 0.11 & $+44^{* *}$ \\
\hline Spanish (lang-) & 783 & 0.06 & 820 & 0.08 & 802 & 0.07 & $+37^{* *}$ \\
\hline \multicolumn{8}{|l|}{ Spanish } \\
\hline Spanish (lang + ) & 787 & 0.03 & 819 & 0.16 & 803 & 0.10 & $+32 * *$ \\
\hline English (lang-) & 765 & 0.08 & 798 & 0.11 & 782 & 0.01 & $+33^{* *}$ \\
\hline \multicolumn{8}{|c|}{ Experiment 3B: Blocked speeded } \\
\hline \multicolumn{8}{|l|}{ English } \\
\hline English (lang+) & 547 & 0.58 & 590 & 1.16 & 569 & 0.87 & $+43^{* *}$ \\
\hline Spanish (lang-) & 588 & 0.37 & 612 & 0.71 & 600 & 0.54 & $+24^{* *}$ \\
\hline \multicolumn{8}{|l|}{ Spanish } \\
\hline Spanish (lang+) & 561 & 0.82 & 582 & 0.69 & 572 & 0.76 & $+21^{* *}$ \\
\hline English (lang-) & 587 & 0.55 & 625 & 1.63 & 606 & 1.09 & $+38^{* *}$ \\
\hline
\end{tabular}

Note. Statistical significance was calculated by making planned comparisons of individual data points. This procedure involves the use of the mean square error of the entire interaction and is more conservative than using one-way analyses of variance or $t$ tests. Lang + and lang $-=$ linguistically congruent and incongruent, respectively; SEM + and SEM - = semantically congruent and incongruent, respectively.

${ }^{* *} p<.05$.

(linguistic congruence) within-subjects factorial design. There was a main effect of semantic congruence that was significant across subjects and items, $F_{1}(1,14)=19.360, p<.001, M S E=$ $2,164.60 ; F_{2}(1,200)=12.020, p<.001, M S E=4,504.31$, reflecting faster reaction times in the semantically congruent condition. No other effects reached significance. As noted above, participants showed equivalent semantic priming in both the within- and between-language conditions. Cell means are summarized in Table 5, and the respective within- and between-language semantic priming effects are illustrated in Figure 5A.

Comparisons of Experiments $1 A$ and $3 A$. Priming scores from Experiments $1 \mathrm{~A}$ and $3 \mathrm{~A}$ were placed in a 2 (experiment) $\times$
2 (text language) $\times 2$ (linguistic) ANOVA. This yielded a main effect of linguistic condition, $F_{1}(1,28)=5.927, p<.022$, $M S E=1,746.89$, with greater priming in the within-language condition (i.e., $50 \mathrm{~ms}$ vs. $11 \mathrm{~ms}$ in Experiment $1 \mathrm{~A}$ and $36 \mathrm{~ms}$ vs. $35 \mathrm{~ms}$ in Experiment $3 \mathrm{~A}$ ). There was also a significant Experiment $\times$ Linguistic interaction, $F_{1}(1,28)=4.382, p<$ $.045, M S E=1,746.89$ (see Figure 6). This reveals that the difference between the within- and between-language priming conditions is larger in the normal than in the delayed condition.

Experiment $3 \mathrm{~A}$ used a mixed design, but it revealed a very different pattern from the mixed designs in Experiment $1 \mathrm{~A}$ and $2 \mathrm{~A}$. In Experiment $1 \mathrm{~A}$, there was no cross-language

Table 5

Tests of the Two-Stage Model for Within-Versus Between-Language Priming

\begin{tabular}{|c|c|c|c|c|c|c|c|}
\hline \multirow[b]{2}{*}{ Variable } & \multirow[b]{2}{*}{ Prediction } & \multicolumn{6}{|c|}{ Finding } \\
\hline & & $\operatorname{Exp} 1 A$ & Exp 1B & $\operatorname{Exp} 2 \mathrm{~A}$ & Exp 2B & $\operatorname{Exp} 3 A$ & Exp 3B \\
\hline Reaction time (RT) & Within RT $<$ between RT & no & no & no & yes & - & yes \\
\hline \multicolumn{8}{|l|}{ Expectations } \\
\hline \multirow[t]{2}{*}{ Low (mixed) } & Priming within & yes & - & yes & 一 & yes & - \\
\hline & No priming between & yes & - & yes $^{\mathbf{a}}$ & - & - & - \\
\hline \multirow{3}{*}{ High (blocked) } & Priming within & - & yes & - & yes & - & - \\
\hline & Priming between & - & yes & - & yes & - & - \\
\hline & Within $>$ between (additive priming) & - & no & - & yes $^{b}$ & - & - \\
\hline \multirow[t]{2}{*}{ Visual degradation } & Increases priming within (Exp 1 vs. 2 ) & - & - & no & no & - & - \\
\hline & Does not increase priming between (Exp 1 vs. 2$)$ & - & - & yes & yes & - & - \\
\hline \multirow[t]{2}{*}{ Delayed naming (mixed only) } & Priming between & - & - & - & - & yes & - \\
\hline & Within $>$ between & - & - & - & - & no & - \\
\hline \multirow[t]{3}{*}{ Speeded naming (blocked only) } & Priming within & - & - & - & - & - & yes \\
\hline & No priming between & - & - & - & - & - & no \\
\hline & Within $>$ between & - & - & - & - & - & no \\
\hline
\end{tabular}

Note. Dashes indicate that a prediction was not tested in an experiment; Exp = experiment.

aSpanish text only. bEnglish text only. 
A) Experiment 3A: Mixed design with delayed naming

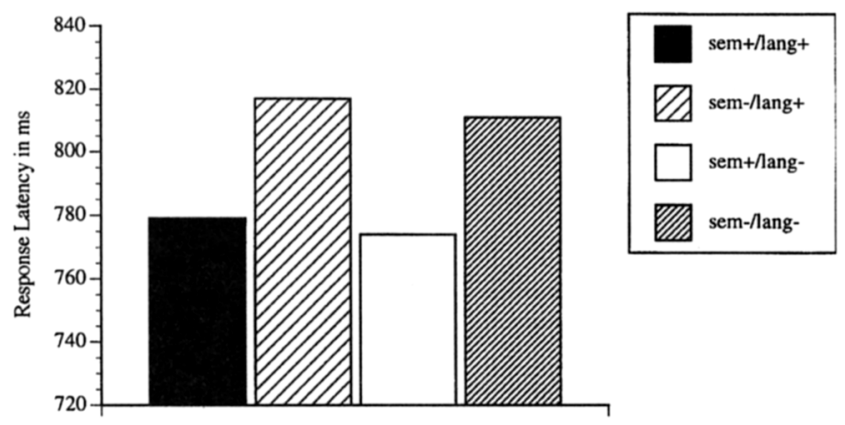

B: Experiment 3B: Blocked design with speeded naming

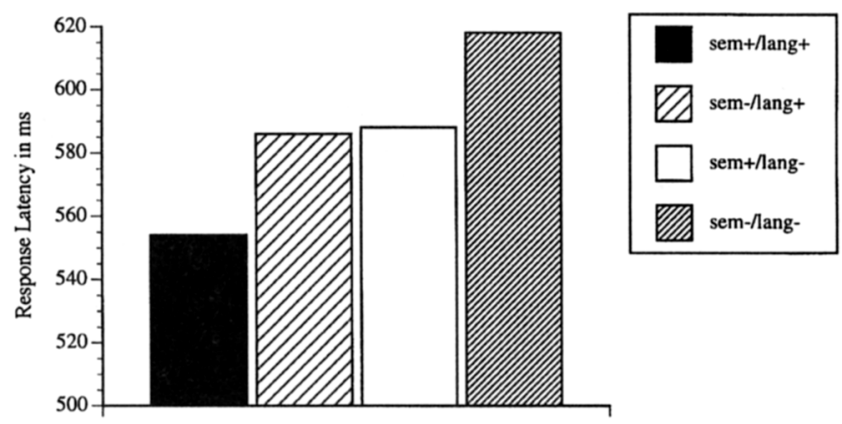

Figure 5. Semantic $\times$ Linguistic interactions in Experiment 3. Sem + and sem- = semantically congruent and incongruent, respectively; lang + and lang $-=$ linguistically congruent and incongruent, respectively.

priming in either language. Experiment $2 \mathrm{~A}$ revealed some between-language priming when English was the text language but never at levels equivalent to within-language priming. Experiment 3A showed robust, across-the-board betweenlanguage priming equal in magnitude to within-language priming in each language. That is, cross-language priming is a

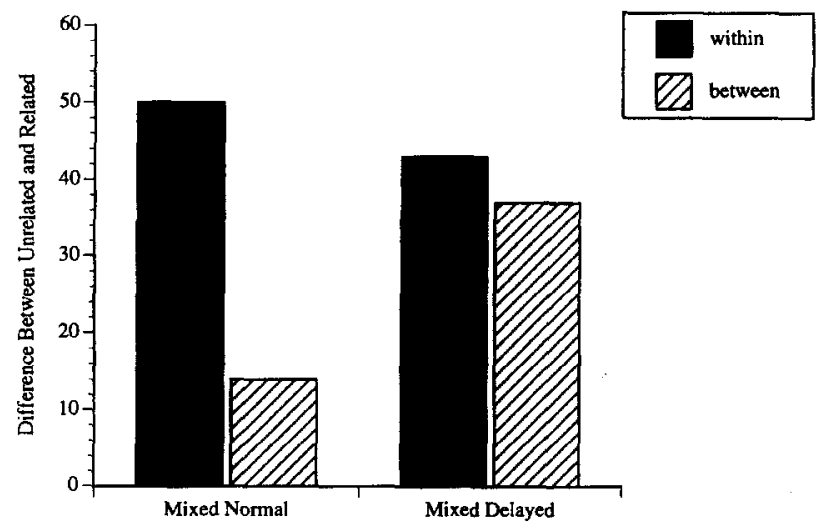

Figure 6. Experiment $\times$ Linguistic interaction for Experiments $1 \mathrm{~A}$ and $3 \mathrm{~A}$ combined. robust effect even in the mixed design but only when a participant is given additional time to process the stimuli. This supports the idea that cross-language priming is a postlexical integration effect (Grainger \& Beauvillain, 1988; Keatley \& de Gelder, 1992). Notice, however, that between-language priming did not exceed within-language effects as we might expect if the lexical component of within-language priming had decayed across the delay period. Apparently participants can maintain semantic activation across that delay period in both languages, presumably because of strategic enhancement (Neely, 1991).

\section{Experiment 3B: Cross-Modal Word Pronunciation in a Blocked Design Using Speeded Naming}

\section{Method}

The participants were 15 University of California, San Diego undergraduates recruited through announcements made on campus and through word of mouth. The mean age of the group was 20.3 years $(S D=2.45)$. This group had spent 18 years speaking English and 19.1 years speaking Spanish. Four of the individuals considered both Spanish and English to be their native language. Two participants considered English to be their native language, and the rest considered Spanish to be their native language. All participants were currently enrolled in college. As in Experiment 1B, individuals were given both an English-bilingual version and the Spanish-bilingual version of the experiment in two separate sessions. Each participant was paid $\$ 5$ for each hour of participation.

\section{Results}

Error rate. The error rate was below $1 \%$ and was not subjected to further analyses.

Difference scores. Priming scores were calculated with the same method as the one described in Experiment $1 \mathrm{~A}$. These scores were placed in a 2 (text language) $\times 2$ (between-within) ANOVA, which yielded no significant main effects and no interaction. In other words, as in our results for Experiment $1 \mathrm{~B}$ (blocked design under normal viewing conditions), similar amounts of priming were obtained in both the within- and the between-language conditions $(M=36 \mathrm{~ms})$. Cell means are summarized in Table 5.

Response times across experimental conditions. The raw response latencies were used for a 2 (language) $\times 2$ (semantic congruence) $\times 2$ (linguistic congruence) within-subjects factorial design. There was a significant main effect of semantic congruence that was significant across subjects and items, $F_{1}(1$, $14)=18.940, p<.000, M S E=1,576.33 ; F_{2}(1,280)=10.130$, $p<.002, M S E=6,959.75$, reflecting faster reaction times in the semantically congruent condition. In addition, there was a significant main effect of linguistic congruence across subjects and items, $F_{1}(1,14)=18.940, p<.000, M S E=1,576.33 ; F_{2}(1$, $280)=7.010, p<.009, M S E=6,959.75$, reflecting the fact that individuals responded faster to a word that was linguistically congruent than to one that was not. As noted above, individuals showed semantic priming in both the within- and betweenlanguage conditions. In fact, there was no reliable interaction between linguistic and semantic congruence. Cell means are summarized in Table 4, and the respective within- and betweenlanguage priming effects are illustrated in Figure 5B. 
Comparisons of Experiments $1 B$ and $3 B$. Priming scores from Experiments $1 B$ and $3 B$ were placed in a 2 (experiment) $\times$ 2 (text language) $\times 2$ (linguistic) ANOVA. This yielded a significant Text Language $\times$ Linguistic interaction, $F_{1}(1,28)=$ $5.080, p<.032, M S E=1,361.08$. This reveals that the within-language priming is larger than between-language priming when English is the text language ( $52 \mathrm{~ms}$ vs. $31 \mathrm{~ms}$ ) but not when Spanish is the text language (i.e., $27 \mathrm{~ms}$ vs. $37 \mathrm{~ms}$ ). Notice that there are no significant interactions between experiments in terms of priming.

The results from this experiment showed that predictability is the most important variable in the elicitation of crosslanguage priming. Assuming that the cross-language effect is strategic and postlexical, it appears that such strategic effects can occur even at the limit of response production as long as bilingual individuals know what language to expect. It remains to be seen, however, whether there is a breaking point as we decrease exposure time and increase speed constraints.

\section{General Discussion}

Table 1 outlines a series of empirical tests for the difference between lexical and postlexical processing, together with predictions for performance by bilingual individuals if it is the case that within-language priming is a lexical effect and between-language priming is a postlexical effect. It is important to consider that the majority of studies that have looked at bilingual language processing have used single word primes, not sentential or discourse primes. Although it is clear that single-word priming is different from the task that we have used, it is important to consider how much a theory of bilingual-lexical priming can explain our current results. In addition, it is important to consider how our findings differ from previous ones. Table 5 summarizes results from six experiments, pointing out which of these predictions were confirmed.

In Experiment 1A, bilingual participants were asked to read and pronounce words under normal visual conditions in an auditory context, but they could not guess the language in which target words would appear (i.e., the mixed design). We hypothesized that this is a situation in which unpredictability is the highest. Under these circumstances, priming was obtained only in the within-language condition, confirming predictions based on the two-stage model. However, we did not find faster reaction times overall in the within-language condition as we might have expected if word recognition in the cross-language condition always requires an extra postlexical step (i.e., some kind of translation process).

In Experiment 1B, participants were again asked to read and pronounce words under normal visual conditions in an auditory context, but this time the target language was predictable (i.e., the blocked design). In this situation, we obtained equivalent semantic priming in both the within- and acrosslanguage conditions. Taken together, the existence of crosslanguage priming in the blocked design and its absence in the mixed design are compatible with predictions based on the two-stage model (Table 5). However, there was no evidence for additivity of lexical and postlexical priming (i.e., priming was not significantly larger in the within-language condition).
In addition, the predicted main effect of linguistic congruity on reaction times also did not occur in this experiment (i.e., lexical within-language reaction times were no faster overall than postlexical between-language reaction times).

In Experiment $2 \mathrm{~A}$, participants were presented with visually degraded stimuli in a mixed design. According to predictions based on the two-stage model, visual degradation ought to increase the magnitude of within-language priming effects, while leaving between-language effects unchanged. This prediction is based on the assumption that lexical activation has more opportunity to spread from prime to target as participants struggle to decode the degraded stimulus. Although reaction times were indeed substantially slower under visual degradation (approximately a 130-ms difference in word-onset latencies between Experiments $1 \mathrm{~A}$ and $2 \mathrm{~A}$ ), there was no overall increase in the amount of semantic priming in any condition-in contrast with other reports in the literature on the effects of visual degradation with monolinguals. We did find a significant interaction between semantic and linguistic congruence (as in Experiment 1A), indicating an absence of semantic priming across the language boundary. This result is in line with our prediction that visual degradation would have no effect on strategic, postlexical processes. However, a more detailed look at our results suggests that significant crosslanguage priming did emerge when participants were listening to English (but not when they were listening to Spanish).

For the most part, our participants were native Spanish speakers who learned English when they went to school at the age of five. All of them are currently immersed in an Englishspeaking environment. The specific characteristics of this population might make them more proficient in English, a language that was not their first language. This was seen in the data. Apparently the increase in difficulty created by visual degradation brings out between-language differences in reading and listening proficiency that were not obvious under optimal processing conditions, differences that affect semantic priming across the language boundary. If we assume that visual degradation affects only lexical processes, then these results might mean that cross-language priming is more lexical for these bilingual individuals when Spanish words are inserted into an English discourse passage and are less lexical when English words are inserted into Spanish discourse. However, this would also mean that lexical and postlexical processing must be treated as a continuum-an inconvenience for the discrete two-stage model.

In Experiment 2B, visually degraded stimuli were presented in a blocked design. Results of this experiment reflect a mix of the results obtained in the previous three. In contrast with Experiment $2 \mathrm{~A}$ using a degraded-mixed design, we did find significant cross-language priming in the degraded-blocked design. This mirrors the contrast between the mixed and blocked designs under normal viewing conditions (Experiments $1 \mathrm{~A}$ and $1 \mathrm{~B}$ ), providing further evidence that crosslanguage priming emerges when individuals know what language to expect. In contrast with predictions based on the two-stage model, there was (once again) no significant increase in within-language priming due to visual degradation. We did find evidence for additivity (i.e., within-language priming effects were significantly larger than between-language prim- 
ing effects in contrast with Experiment 1B). However, a more detailed look at these results showed that additivity reached significance only when individuals were listening to English texts. Hence, we have further evidence that priming is influenced by differences between English and Spanish in fluency, recency, or both.

Experiment 3A looked at the mixed design under delayed naming. Participants were asked to wait for a cue before they initiated their responses, slowing down their reaction times by approximately $150 \mathrm{~ms}$. According to the predictions outlined in Table 1, delayed response should enhance between-language priming because postlexical strategies are given ample time to emerge. Furthermore, increasing time for postlexical processing should increase the size of within-language priming as well. Comparing Experiment $3 \mathrm{~A}$ with the same design under normal response conditions in Experiment 1A, we found a significant increase in between-language priming from a nonsignificant 11 $\mathrm{ms}$ to a reliable difference of $34 \mathrm{~ms}$. Thus, our findings confirm that cross-language priming increases when participants are given time to integrate words into the larger sentential context. There was no significant difference in the size of within- versus between-language effects following a response delay. Thus, once again there was no evidence of the additivity between lexical and postlexical priming that might be expected for within-language targets.

Finally, Experiment 3B tested the hypothesis that crosslanguage priming would disappear under speeded conditions, even in the blocked design. This prediction is based on the assumption that strategic effects are postlexical and that such effects take more time than individuals have available when they are pushed to their response limits. In fact, Experiment $3 \mathrm{~B}$ revealed robust cross-language priming and no difference in the magnitude of priming for within- versus betweenlanguage priming, nor was there any evidence for a reduction in cross-language priming relative to Experiment $1 \mathrm{~B}$ (i.e., blocked design with more time to respond). The only evidence for an effect of speeded response lies in a main effect of linguistic congruity on overall reaction times (i.e., faster reaction times in the within-language condition collapsed across priming and text conditions). This difference was also observed in the blocked design under visual degradation, but it did not occur under normal viewing conditions or in any experiment using the mixed design. In other words, naming is easier (or at least faster) when the target word matches the text language, but this difference is observed only in the blocked design (when individuals know what language to expect), and even then it occurs only under difficult processing conditions (i.e., visual degradation or speeded response). Given these constraints, the response-time difference provides little evidence for a difference between lexical and postlexical processing.

The results from all six experiments are quite clear in one respect. Cross-language priming appears when participants know what language to expect, when they have ample time to generate a response, or both. If these conditions do not hold, then semantic priming does not spread across the language boundary. In this respect, our results are consistent with a lexical-postlexical view of within-between-language priming.
There are, however, several findings that make us wary of the two-stage model as an account of lexical processing in bilinguals.

First, there was one exception to this broad generalization: cross-language priming did appear in the mixed design when bilinguals were listening to English texts and recognizing Spanish words under degraded conditions.

Second, we did not find consistent evidence for additivity of lexical and postlexical effects. If these effects are additive, then within-language priming should be larger than betweenlanguage priming in the blocked design. This was true only in one case: when participants were listening to English text and reading visually degraded words.

Third, we did not find that within-language reaction times were faster overall as we might expect if between-language reaction times reflect an extra (postlexical) step. In fact, word-pronunciation reaction times in the cross-language condition were remarkably fast. If performance in the crosslanguage condition is strategic, then at the very least we have to consider the possibility that such strategies are fast enough to use in everyday life.

Finally, the two-stage model must be amended to account for the following differences between Spanish and English in these bilingual individuals: (a) Priming effects tended to be larger overall when participants were listening to English and reading degraded words; (b) there was evidence for crosslanguage priming even in the mixed design when bilinguals were listening to English and reading degraded Spanish words; (c) within-language priming was particularly large in the blocked design when participants were listening to English and reading degraded English words (i.e., additivity in English but not in Spanish). These three results point to the possibility that priming is more robust for the language that bilinguals are using most often in their everyday lives. Furthermore, it suggests that differences in fluency that are thought to have an effect on a bilinguals' lexical and conceptual memory (Altarriba, 1992; Kroll \& Stewart, 1994) may also have an effect in on-line language processing. Clearly, models of bilinguallanguage processing should consider whether the differences in fluency are similar or different depending on the task at hand (translation of picture, conceptual priming, lexicalsemantic priming, translation priming, discourse-level priming under visual degradation, etc.).

The absence of cross-language priming in bilinguals has been taken as evidence of structural separation between two lexicons. In the present experiments, it might seem logical to conclude that the presence of cross-language priming in the blocked design and its absence in the mixed design support the view that there are two lexicons and that lexical activation spreads in one language only. However, several investigators have begun to question the very existence of purely nonstrategic lexical priming even in monolinguals. For example, Smith et al. (1994) presented individuals with prime-target word pairs and identity word pairs with a short prime presentation $(84 \mathrm{~ms})$ and a long prime presentation $(280 \mathrm{~ms})$. Half of the participants were tested in a blocked design in which only the short prime durations were seen for the first half of the session and only the long prime durations were seen for the second 
half of the session. The other half of the participants were tested in a mixed design in which long and short prime durations were presented in the same session. The results revealed semantic priming for the long prime durations in both the mixed and the blocked conditions. For short prime durations, there was only semantic priming in the blocked condition. Furthermore, there was identity priming for the short SOA pairs even in the mixed design, which leads us to conclude that participants always accessed the prime. Hence, the presence of semantic priming at short SOAs in the blocked design (and its absence in the mixed design) must mean that automatic semantic priming is affected by expectations. In the same vein, a recent study by Henik et al. (1994) showed that semantic-priming effects at very short SOAs are affected by cognitive overload from a secondary task, further evidence against the putative, obligatory nature of short-term semantic priming. These findings for monolinguals with a single lexicon mimic our findings for bilinguals who are working across the language boundary.

Where does this leave us? Despite accumulating evidence against the two-stage model, it is still the dominant view. Most investigators do not question the existence of a contrast between lexical and postlexical processing, although there is lively debate about where the line should be drawn (i.e., whether semantic, associative, or both priming effects are lexical, Balota, 1989; Neely, 1991; or whether they are postlexical, Borowsky \& Besner, 1993; Forster, 1990; Glaser, 1992). A few investigators have proposed that there are feedback loops from the semantic system to the orthographic system which can constrain lexical access under some conditions. For example, Smith et al. (1994) have proposed a threshold-activation model in which the criterion for word recognition can be set high or low to account for variations in semantic or perceptual conditions or both. Finally, researchers have begun to consider the role of expectation or intention in semantic priming. Duchek and Balota (1993) and Bowles (1993) have suggested that the increase in priming and contextual reliance observed with older adults may be the result of a compensatory mechanism that is used when cognitive processing is slowed. Similarly, Mackay (1987) has differentiated between priming (which is how prepared a set of nodes is for activation) and activation (which is the more traditional sense of the word). In his view, the intention of an individual can enhance or suppress the magnitude of activation by increasing or decreasing priming. In the future, theories of lexical-semantic priming may not only need to take into account the effect of attentional mechanisms but may also need to elucidate the attentional trade-offs (i.e., compensatory strategies) that individuals regularly use in performing an experiment. To account for these trade-offs, it may be important to consider issues such as priming and activation as conceptualized by Mackay (1987).

Although we do not have a full-blown alternative to the standard two-stage model in bilinguals or monolinguals, we can suggest some new directions. First, it may be useful to consider an account of bilingual language processing similar to the proposal by Smith et al. (1994) in which word-recognition thresholds are adjusted according to environmental conditions. Second, our account must take into account the notion that reading a word aloud does not necessarily involve accessing its meaning (see Balota, 1989, for further discussion). Besner and Smith (1992) have suggested that there are two pathways between an orthographic-input lexicon (used in the recognition of printed words) and a phonological-output lexicon. One of these pathways is direct, and the other is mediated by a semantic system in which the traditional effects of spreading activation occur. Previous research suggests that bilinguals can detach cross-language lexical items from semantic processing. We suggest that bilinguals in the current experiment may use direct reading to curtail the slowdown in processing of cross-language words. It is unclear if this is a product of compensatory strategies (i.e., bilinguals actively ignore semantic information for cross-language lexical items) or a product of the nature of activation of cross-language candidates (i.e., semantic information is activated more slowly because lexical information is). However, it is clear that reading can be done without effects of meaning. Future studies should attempt to provide a clearer understanding of where in the language-processing system this occurs (i.e., whether it is a product of the lexical level or the semantic level).

In addition to attentional issues, an account of bilingual language processing will have to include baseline differences in recognition thresholds in each language due to the bilinguals' recent history, including absolute differences in fluency ("my Spanish never was that good") and differences due to recency of use ("my Spanish is a little rusty"). Most studies have looked at language fluency as a static characteristic (first vs. second language, etc.). However, most bilinguals report changes in fluency that are mediated by how much and how recently they have used a language. In that regard, it may also prove necessary to differentiate between different modalities of use (e.g., reading vs. listening). Thus, it may be that some individuals read much better in one language than in the other but speak both languages quite well. We also considered whether cloze probability might play a role in cross-language priming. However, on reviewing our stimuli we concluded that for the most part these stimuli were medium in cloze probability. There were some items that were of higher cloze probability than others. Unfortunately, we did not systematically manipulate the cloze probability of the sentences. Altarriba et al. (1992) have suggested that cloze probability plays an important role in bilingual word recognition. Future studies should consider how bilinguals may use their expectations about the semantic and linguistic environment to lower or raise the thresholds for words within this uneven landscape of default baselines.

Semantic priming in bilinguals takes place (or does not take place) against this complex background. We know very little about the process by which semantic activation spreads across the language border. Indeed, it is no longer clear that spreading activation is the right metaphor (Forster, 1990; Foss \& Ross, 1983; Foss \& Speer, 1983). If semantic effects were purely facilitative, then we would expect to find faster reaction times overall in those conditions where priming takes place and slower reaction times overall when priming does not take place. But as one can see from the summary of results in Table 5 , this is not always the case. For example, in Experiments $1 \mathrm{~A}$ 
and $2 \mathrm{~A}$ we had significant within-language priming effects but no between-language priming, and yet there was no significant main effect of linguistic congruity on reaction times. In other words, priming did not make participants faster! A possible explanation for this paradox comes from examination of the data in Figures $2 \mathrm{~A}$ and 3A. Looking first at the +SEM (semantically congruent) conditions within and between languages, notice that the within-language condition does appear to be somewhat faster, which is in line with a spreadingactivation account of priming. However, looking at the -SEM (semantically incongruent) conditions within and between languages, we can see that the within-language condition is actually somewhat slower. In other words, priming seems to involve movement in two directions, which is consistent with the idea that priming involves facilitation for semantically compatible items and inhibition for semantically incompatible items. Hence, priming can occur even though overall reaction time does not go down. Because it is so difficult to find a convincing neutral baseline for connected discourse (i.e., there is no such thing as a neutral paragraph), we cannot draw firm conclusions about facilitation versus inhibition in this experiment. However, it is at least possible that the priming effects observed in these experiments involve a combination of "spreading inhibition" (i.e., inhibition of semantically inappropriate words) as well as "spreading facilitation" (i.e., excitation of semantically appropriate words). If this account of semantic priming is correct, then the absence of cross-language priming under some conditions may reflect linguistic inhibition of semantic inhibition rather than the simple absence of priming. This is a possibility that we are actively pursuing, in experiments with competitive or inhibitory priming paradigms or both.

From the evidence presented in these experiments, it is quite clear that mediating between two language systems involves a set of flexible processes that are extremely sensitive to changing environmental conditions. It would be exceedingly useful if a lifetime of knowledge about the processing requirements for each context could be brought to bear, tuning the language processor for the task at hand. For example, the requirements for a code-switching situation are undoubtedly different from the requirements for a single-language conversation with a monolingual partner. Indeed, in many immigrant households, a family member must be ready to speak Language 1 with grandmother (who knows no English and therefore can produce none), Language 2 with a young cousin (who never learned Spanish in the first place), and both languages in alternating patterns that vary in degree for parents, brothers, and family friends. In a situation like the one described above, we need not assume that a great deal of conscious effort is required to move from one mode of processing to another. Although we propose that these computations occur rapidly and unconsciously in everyday situations, there may still be small costs that can be measured only in milliseconds. We feel that future studies should consider more carefully the nonlexical and lexical variables that may play a strong role in on-line semantic processing by bilinguals. In doing so, it may become clearer what types of contextual cues are used by speakers who on an everyday basis perform rapid integration of meaning across the language boundary.

\section{References}

Altarriba, J. (1991). Is there semantic priming across a bilinguals' two languages? Unpublished manuscript, University of Massachusetts at Amherst.

Altarriba, J. (1992). The representation of translation equivalents in bilingual memory. In R. J. Harris (Ed)., Cognitive processing in bilinguals (pp. 157-174), Amsterdam, the Netherlands: NorthHolland.

Altarriba, J., Kroll, J. F., Sholl, A., \& Rayner, K. (in press). Reading mixed-language sentences: The influence of lexical and conceptual constraints. Language \& Cognitive Processes.

Balota, D. A. (1989). The role of meaning in word recognition. In D. A. Balota, G. B. Flores d'Arcais, \& K. Rayner (Eds.), Comprehension processes in reading (pp. 9-32). Hillsdale, NJ: Erlbaum.

Balota, D. A., \& Lorch, R. F. (1986). Depth of automatic spreading activation: Mediated priming effects in pronunciation but not in lexical decision. Journal of Experimental Psychology: Learning, Memory and Cognition, 12, 336-345.

Becker, C. A., \& Killion, T. H. (1977). Interaction of visual and cognitive effects in visual word recognition. Joumal of Experimental Psychology: Human Perception and Performance, 3, 389-401.

Besner, D., \& Smith, M. (1992). Models of visual word recognition: When obscuring the stimulus yields a clearer view. Joumal of Experimental Psychology: Leaming, Memory and Cognition, 18, 468482.

Borowsky, R., \& Besner, D. (1993). Visual word recognition: A multistage activation model. Joumal of Experimental Psychology: Learning, Memory and Cognition, 19, 813-840.

Bowles, N. (1993). Semantic processes that serve picture naming. In J. Cerella, J. M. Rybash, W. Hoyer, \& M. L. Commons (Eds.), Adult information processing: Limits on loss (pp. 303-326). San Diego, CA: Academic Press.

Duchek, J. M., \& Balota, D. A. (1993). Sparing activation processes in older adults. In J. Cerella, J. M. Rybash, W. Hoyer, \& M. L. Commons (Eds.), Adult information processing: Limits on loss (pp. 383-406). San Diego, CA: Academic Press.

Duffy, S. A., Henderson, J. M., \& Morris, R. K. (1989). The semantic facilitation of lexical access during sentence processing. Joumal of Experimental Psychology: Leaming, Memory and Cognition, 15, 791801.

Favreau, M., \& Segalowitz, N. (1983). Automatic and controlled processes in reading a second language. Memory \& Cognition, 11, 565-574.

Forster, K. I. (1990). Lexical processing. In D. N. Osherson \& H. Lasnik, (Eds.), Language: An invitation to cognitive science (pp. 95-131). Cambridge, MA: MIT Press.

Foss, D., \& Ross, J. R. (1983). Great Expectations: Context effects during sentence processing. In G. Flores D'Aracais \& R. J. Jarvella (Eds.), The process of language understanding (pp. 169-191). Chichister, England: Wiley.

Foss, D., \& Speer, S. R. (1983). Global and local context effects in sentence processing. In R. Hoffman \& D. Palermo (Eds.), Cognition and the symbolic processes: Applied ecological perspectives (pp. 115139). Hillsdale, NJ: Erlbaum.

Glaser, W. M. (1992). Picture naming. Cognition, 42, 61-105.

Grainger, J., \& Beauvillain, C. (1988). Associative priming in bilinguals: Some limits of interlingual facilitation effects. Canadian Joumal of Psychology, 42, 261-273.

Henik, A., Freidrich, F. J., \& Kellog, W. A. (1983). The dependence of 
semantic relatedness effects upon prime processing. Memory \& Cognition, 11, 366-373.

Henik, A., Tzelgov, J., Friedrich, F., \& Levi-Manor, T. (1994, November). Cognitive load reduces priming effects. Paper presented at the meeting of the Psychonomic Society, St. Louis, MO.

Hernandez, A. (1992). Interdependence vs. independence: Evidence from a cross-modal paradigm. Unpublished master's thesis, University of California, San Diego, La Jolla.

Hernandez, A., \& Bates, E. (1994). Interactive activation in normal and brain-damaged individuals: Can conext penetrate the lexical module? Linguistiche Berichte 6, 145-167.

Juilland, A., \& Chang-Rodriguez, E. (1964). The romance languages and their structures. The Hague: the Netherlands: Mouton.

Keatley, C., \& de Gelder, B. (1992). The bilingual primed lexical decision task: Cross-language priming disappears with speeded responses. European Joumal of Cognitive Psychology, 4, 273-292.

Kroll, J. F., \& Stewart, E. (1994). Category inference in translation and picture naming: Evidence for asymmetric connections between bilingual memory representations. Joumal of Memory and Language, $33,149-174$.

KuCera, H., \& Francis, W. N. (1967). Computational analysis of present-day American English. Providence, RI: Brown University Press.

Liu, H., Bates, E., \& Li, P. (1992). Sentence interpretation in bilingual speakers of English and Chinese. Applied Psycholinguistics, 13, 451-484.

MacKay, D. G. (1987). The organization of perception and action: $A$ theory for language and other cognitive skills. New York: SpringerVerlag.

Marangolo, P., Di Pace, E., \& Pizzamiglio, L. (1993). Priming effect in a color discrimination task. Perceptual and Motor Skills, 77, 259-269.

Marslen-Wilson, W., \& Tyler, L. K. (1987). Against modularity. In J. L. Garfield (Ed.), Modularity in knowledge representation and naturallanguage understanding (pp. 37-62). Cambridge, MA: MIT Press.

Meyer, D. E., Schvaneveldt, R. W., \& Ruddy, M. G. (1975). Loci of contextual effects on visual word recognition. In P. M. A. Rabbitt \& S. Dornic (Eds.), Attention and performance $V$ (pp. 98-118). New York: Academic Press.

Morris, R. K. (1994). Lexical and message-level sentence context effects on fixation times in reading. Journal of Experimental Psychology: Leaming, Memory and Cognition, 20, 92-103.

Neely, J. H. (1991). Semantic priming effects in visual word recognition: A selective review of current findings and theories. In D.
Besner \& G. W. Humphreys (Eds.), Basic processes in reading: Visual word recognition (pp. 264-336). Hillsdale, NJ: Erlbaum.

Neely, J. H., Keefe, D. E., \& Ross, K. (1989). Semantic priming in the lexical decision task: Roles of prospective/retrospective processing theory. In G. H. Bower (Ed.), The psychology of leaming and motivation: Advances in research and theory (Vol. 24, pp. 207-248). New York: Academic Press.

O'Seaghdha, P. G. (1989). The dependence of lexical relatedness effects on syntactic connectedness. Joumal of Experimental Psychology: Leaming, Memory and Cognition, 15, 73-87.

Posner, M. C., \& Snyder, C. (1975). Facilitation and inhibition in the processing of signals. In P. M. A. Rabbitt \& S. Dornic (Eds.), Attention and Performance $V$ (pp. 669-683). New York: Academic Press.

Seidenberg, M. S., Tanenhaus, M. K., Leiman, J. M., \& Bienkowski, M. (1982). Automatic access of the meanings of ambiguous words in context: Some limitations of knowledge-based processing. Cognitive Psychology, 14, 489-537.

Seidenberg, M. S., Waters, G. S., Sanders, M., \& Langer, P. (1984). Pre- and postlexical loci of contextual effects on word recognition. Memory \& Cognition, 12, 315-328.

Smith, L. C., Theodor, L., \& Franklin, P. E. (1983). On the relationship between contextual facilitation and depth of processing. Journal of Experimental Psychology: Learning, Memory, and Cognition, 9, 697-712.

Smith, M. C., Besner, D., \& Miyoshi, H. (1994). New limits to automaticity: Context modulates semantic priming. Joumal of Experimental Psychology: Learning, Memory and Cognition, 20, 104-115.

Stanovich, K. E., \& West, R. F. (1983). On priming by a sentence context. Joumal of Experimental Psychology: General, 112, 1-36.

Swinney, D. A. (1979). Lexical access during sentence comprehension: (Re)consideration of context effects. Joumal of Verbal Leaming \& Verbal Behavior, 18, 645-659.

Tweedy, J. R., Lapinski, R. H., \& Schvaneveldt, R. W. (1977). Semantic-context effects on word recognition: Influence of varying the proportion of items presented in an appropriate context. Memory \& Cognition, 26, 259-275.

Tzelgov, J., \& Eben-Ezra, S. (1992). Components of the betweenlanguage semantic priming effect. European Joumal of Cognitive Psychology, 4, 253-272.

Van Petten, C., \& Kutas, M. (1987). Ambiguous words in context: An event-related potential analysis of the time course of meaning activation. Journal of Memory and Language, 26, 188-208. 


\section{Appendix A}

\section{Sample Texts for Experiments 1-3}

\section{Sample English Text}

The number of vehicles and people that move about a city in a course of a day can be quite large. Normally, the traffic is directed by policemen or traffic lights. The officers and the signals help to indicate who has the right of way at any given time. There are certain times of the day when traffic gets the heaviest. These hours are usually before people go to work and after they leave work. During these times, traffics jams can ofter occur. Sometimes the traffic gets so heary, that it is faster to walk somewhere than it is to drive.

\section{Sample Spanish Text}

El numero de vehículos y personas a pie que andan a diario por una ciudad es muy grande. Normalmente se regula et tráfico mediante policías urbanos o semaforos. Estos por lo regular dan la preferencia de paso a los peatones o a los carros. Hay momentos cuando el tráfico es mas pesado. Estas horas suelen ser a la hora de entrar y salir del trabajo. Durante estas horas se pueden producir embotellamientos mas seguido. A veces el trafico se pone tan pesado que resulta mas rapido andar a pie que in carro.

\begin{tabular}{lll}
\multicolumn{3}{c}{ Sample Targets } \\
\hline $\begin{array}{c}\text { Mixed Design } \\
(+\mathrm{L} /-\mathrm{L})\end{array}$ & \multicolumn{2}{c}{$\begin{array}{c}\text { Blocked } \\
\text { Design }\end{array}$} \\
\hline city & English & Spanish \\
traffic & city & ciudad \\
snakes & traffic & trafico \\
milagro & snakes & condes \\
horas & bargain & tocino \\
gobierno & hours & horas \\
standard & voice & gobierno \\
regalar & nuclear & asiduo \\
libro & drive & fusilar \\
\hline Note. & $+\mathrm{L}=$ linguistically congruent; $-\mathrm{L}=$ linguistically incongru- \\
ent. & & book
\end{tabular}

Received December 7, 1994

Revision received July 13, 1995

Accepted August 31, 1995 